\title{
The Interannual and Interdecadal Variability in Hurricane Activity
}

\author{
Anthony R. Lupo \\ Department of Soil, Environmental, and Atmospheric Sciences \\ 302 E Anheuser Busch Natural Resources Building \\ University of Missouri - Columbia \\ MO, USA
}

\section{Introduction}

While the interannual variability of hurricane activity has been studied extensively over the last few decades, there has been a recent increase in the interest of the interdecadal variability of hurricane activity (e.g., Henderson-Sellers et al. 1998; Emanuel, 2005; Webster et al. 2005; Schultz, 2007; Lupo et al. 2008; Ng and Chan, 2010) worldwide. This interest has been prompted by several active hurricane years in the Atlantic Ocean basin, the occasional occurrence of tropical cyclones in the South Atlantic in the last decade (e.g. Reagan et al. 2005; McTaggart-Cowan et al. 2006), as well as concern about changes in hurricane frequency that may be a result of changes in Earth's climate. These active years in the Atlantic which garnered much media attention included the 2004 season during which several storms struck the Southeast United States including Florida, and the 2005 season which was the most active hurricane season since 1933, and included the deadly hurricane Katrina.

Some studies, e.g., Lupo and Johnston (2000) (hereafter L.DO), and then Lupo et al. (2008), suggested that there is significant interdecadal variability in the occurrence and intensity of Atlantic region hurricane activity, and that this variability may be linked to the Pacific Decadal Oscillation (PDO). More specifically, these studies found that there was a change in the behavior of interannual variability of tropical cyclone (TC) occurrences in the North Atlantic as related to the El Niño and Southern Oscillation (ENSO). During the negative phase of the PDO (1947-1976), they found little ENSO related variability in the number and intensity of hurricanes basin wide. However, during the positive phase of the PDO (1977 1999) they found that there was strong interannual variability in TC occurrences between El Niño and La Niña years. During La Niña years, there were more and stronger hurricanes overall even though there were fewer months with significant hurricane activity. Also, there were more Caribbean and Gulf region hurricanes during La Niña years. Additionally, studies have shown that since 1999 (see Lupo et al. 2007, 2008, and Birk et al. 2010), the Pacific Ocean basin region has reverted back to the negative phase of the PDO.

Recently, Vimont and Kossin (2007) (and Kossin and Vimont, 2007) found a strong correlation in the North Atlantic between accumulated cyclone energy (which is positively correlated with TC activity) and the Atlantic Meridional Mode (AMM). In their work, they also find that the Atlantic Multi-decadal Oscillation (AMO) may excite the AMM on a 
decadal time scale. Thus, these indexes, which quantify the climatological background state, correlate with TC activity on the decadal time scale (AMO) or both the interannual and decadal (AMM) time-scales. Additionally, interdecadal variability as related to the PDO in the tropical and mid-latitude background climatological state have also been demonstrated in other studies (e.g., Deser et al. 2004, 2006, and Deser and Phillips 2006), and additional studies have discussed the synergistic relationship between oceanic and atmospheric conditions needed for an active tropical season (e.g., Zuki and Lupo 2008).

Studies of TC activity in the Eastern Pacific have shown that this area is generally more active than the Atlantic (e.g. Schultz, 2007; Collins, 2007; Lupo et al. 2008; Collins, 2010). The major findings for East Pacific TC activity have demonstrated that the long term trend in this region is decreasing, but the decrease is not statistically significant. Lupo et al. (2008) show that a slightly higher percentage of intense hurricanes occurred in the East Pacific region as compared to the Atlantic region. Collins (2007) shows that the eastern part of the East Pacific ocean basin was the most active in producing TCs, and that the western part was more variable with respect to ENSO due to thermodynamic considerations (atmospheric relative and absolute humidity, sea surface temperatures, vertical motions). Lupo et al. (2008) demonstrate that the seasonal activity (season beginning, peak, and end) was about 15 to 30 days earlier than that in the Atlantic Ocean basin.

These studies referenced above also demonstrated that there were more East Pacific TCs during El Niño years, and that this was mainly accounted for by more TCs becoming intense hurricanes than during La Niña years. The TC season was one or two months longer in El Niño years (Lupo et al. 2008), while more storms formed in the southeast and southwest part of the East Pacific Ocean basin (Collins, 2007). This is likely due to the fact that ENSO years bring warmer waters to the East Pacific region. When breaking down the ENSO years by phase of the PDO, the ENSO-related differences in occurrence and intensity and geographic formation region are accentuated in PDO1 years, but were blurred in PDO2 years. This ENSO and PDO related variability is similar to that occurring in the Atlantic (LJ00).

While the most extensive studies have been performed in the Atlantic Region, there have been studies demonstrating ENSO variability in West Pacific and Northern Indian Ocean region TC occurrence as well (e.g., Chan, 1985; Wu and Lau, 1992; Ng and Chan, 2010). These studies showed similar results for the Pacific Ocean basin as a whole. However, Ramage and Hori (1981), Lander (1994), and Chan and Liu (2004) found no ENSO variability in the overall TC numbers throughout the North Pacific as a whole, but significant variability in the primary TC genesis regions. Since then, studies have shown that the focus of tropical storm activity moves southeastward (northwestward) during El Niño (La Niña) years (e.g., Chan, 1985; Wu and Lau, 1992; Lander, 1994; Wang and Chan, 2002; and Chan 2007, 2009).

Recently, there has been concern that TC frequencies and intensities may be increasing because of climatic (whether attributed to natural or anthropogenic forcing) warming, and several studies have investigated the issue (Henderson-Sellers et al., 1998; Pielke et al., 2005; Emanuel, 2005; Webster et al., 2005; Chan 2009). These studies, however, have shown inconsistent results, and the study of Chan (2009) suggests that the relationship between the atmospheric variables and sea surface temperatures (SSTs) are too complex to determine that warmer SSTs alone can drive increased TC activity.

There has also been some disagreement in the literature regarding the relationship between the QBO and TC activity over the western north Pacific, the North Atlantic or the East 
Pacific. Chan (1995) found that the westerly phase of the QBO was positively correlated with increased tropical cyclone activity over the western north Pacific, which is similar to the results of Gray (1984a) for the Atlantic Ocean basin. However, Lander and Guard (1998) showed that the global TC activity was not significantly correlated to the QBO.

Additionally, Gray (1968) and Gray (1979) discuss the important atmospheric and oceanic factors needed in the development of tropical cyclones. Since then, Zuki and Lupo (2008) and Chan (2009) demonstrate that the interannual variability in TC frequencies is not determined solely by SSTs and their variations. Rather, it appears that SST variations may provide a necessary but not sufficient condition for variations in TC occurrences and/ or intensities. These studies demonstrate that the atmospheric conditions must also be favorable whether one examines dynamic variables (e.g., vorticity or upper level divergence), or thermodynamic variables (latent heating), and that it is possible to have warm SSTs but little or no TC activity (Zuki and Lupo, 2008). Chan (2009) demonstrates that dynamic and thermodynamic considerations may provide a sufficient condition, but that these variables may also be impacted by ENSO. Thus, the effect of ENSO and the PDO on TC activity is to alter the oceanic and atmospheric variables in a way that may be synergistically more or less favorable to TC activity.

The goal of this work is two-fold. The first is to examine TC activity and trends in all the global ocean basins where it occurs, including the South Atlantic. Where appropriate this work will be placed into context with respect to the earlier work of $\mathrm{L} J 0$ and Lupo et al. (2008) and others. Second, the methodologies of LJ00 and Lupo et al. (2008) will be applied to study interannual and interdecadal TC activity globally, as a similar comprehensive study of TC internannual and interdecadal activity, including a partition of such activity into subbasins, is not available elsewhere. Additionally, such a study for Southern Hemisphere activity is not yet available.

\section{Data and methods}

The data and methods are similar to those used by LJ00 and Lupo et al. (2008), and more detail regarding some of these subjects can be found there and in references therein. This study has been expanded to include all the globe's ocean basins and includes tropical storm occurrences as well. This study breaks down the global ocean basins as follows; the North Atlantic, East Pacific, West Pacific, North Indian, Southern Hemisphere (includes South Indian and the South Pacific), and the South Atlantic. A study of the background atmospheric and oceanic variables contributing to TC formation is not performed here as it is beyond the scope of this work.

\subsection{Data}

The TC occurrence and intensity data for all basins were downloaded via the UNISYS website (http:/ / weather.unisys.com), and these data can also be found in other archives (e.g., LJ00). A complete description of these data sets and their reliability (e.g., Landsea 1993) can be found in Jarvinen et al. (1984) for the Atlantic, and Davis et al. (1984) for the East Pacific. In the West Pacific, these data were provided to UNISYS through the Joint Typhoon Warning Center (JTWC) best track data set. As stated by Lander (1994), TCs in the West Pacific Ocean have been monitored by the United States Navy since 1945 and by the United States Air Force since 1947 using aircraft reconnaissance. In 1959, these entities were combined under one command, the JTWC, to track TCs over the western North Pacific. 
Weather satellite observations became routine in 1965, and these observations contributed to all the data sets as well. Lastly, the JTWC also monitors TC activity over the Northern Indian Ocean and the Southern Hemisphere as well. The data are also available via the International Best Track archive for Climate Stewardship Project (http:/ / www.ncdc.noaa.gov/ oa/ ibtracs/ ) (e.g., Ng and Chan, 2010).

In this study, we use the term TC to include both hurricanes and tropical storms (TS) following Lupo et al. (2008), and here tropical storms refer only to those entities that obtained maximum wind speeds between $35-64 \mathrm{kt}$. TC data in the Atlantic basin before 1938 were not used in the study as explained in LJ00, and following their lead, this study only uses Saffir-Simpson (Simpson 1974) hurricane intensity data. In the East Pacific, data before 1970 were not included since all hurricanes before that date were classified as a category one (e.g., see Schultz 2007). In the Indian Ocean and Southern Hemisphere, tropical cyclones were not classified with an intensity value early in the record (1949 to the 1970s). TCs were not regularly categorized until 1977 in the North Indian Ocean and 1980 in the Southern Hemisphere. Thus, the results here will not include TCs before these dates in those regions. In order to eliminate problems with some of the data as discussed in LJ00, we combined hurricane intensity categories (category 1 and 2 - weak; category 3, 4, and 5 intense) following Landsea (1993). Additionally, in some parts of the discussion tropical storms will be referred to as category -0 .

\subsection{Methodology}

The complete archive for the years discussed above for all the ocean basins were examined in this study. The Atlantic Ocean Basin (Fig. 1a) and the East Pacific Ocean Basin (Fig. 1b) are shown here. Arithmetic means and correlations were analyzed, and means were tested for statistical significance using a two-tailed z-score test, assuming the null hypothesis (e.g., Neter et al. 1988). Intensity distributions were also tested using a $\chi^{2}$ statistical test. These distributions were tested using the total sample climatology as the expected frequency and a sub-period as the observed frequency. It has been hypothesized that using the climatological frequency as the "expected" frequency is more appropriate than using an approximated distribution since such analytical distributions (e.g., Poisson distribution) may not adequately represent real-world distributions (e.g., Lupo et al. 1997; LJ00). It should be cautioned that while statistical significance reveals strong relationships between two variables, it does not imply cause and effect. Conversely, relationships that are found to be strong, but not statistically significant may still have underlying causes due to some atmospheric forcing process or mechanism (e.g., Lupo et al. 1997; LJ00).

Finally, the data were stratified by calendar year in the Northern Hemisphere (NH). In the Southern Hemisphere (SH), the tropical cyclone year is defined as the period beginning on 1 July and ending on June 30. We then analyzed the annual and monthly distributions of TC occurrence in order to find both long and short-term trends in season length within both the total sample and each intensity category. The sample was also stratified by sub-basins in the Atlantic Ocean basin following LJ00. The East Pacific Ocean basin was stratified into quadrants divided by $125^{\circ} \mathrm{W}$ and $20^{\circ} \mathrm{N}$ following Collins (2007) and Lupo et al. (2008). The West Pacific Ocean was divided in quadrants by the lines $140^{\circ} \mathrm{E}$ and $20^{\circ} \mathrm{N}$. The North and South Indian Ocean was dived into an east and west basin along $75^{\circ} \mathrm{N}$. In the South Pacific, the ocean basin was divided into west and east along $180^{\circ}$ longitude. TCs were assigned to the basin in which they first reached tropical storm status. 


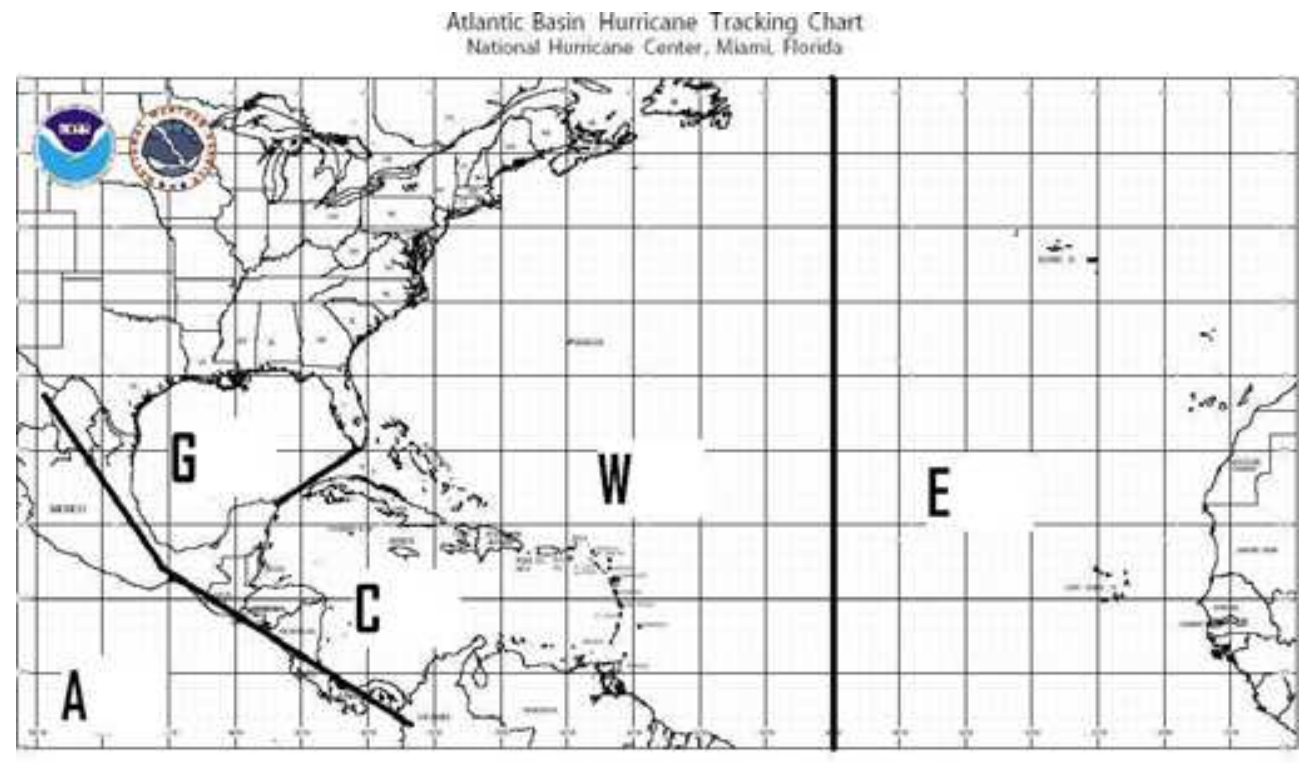

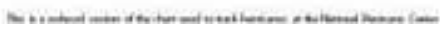

East Pacific Hurricane Tracking Chart

National Hurricane Center, Miami, Florida

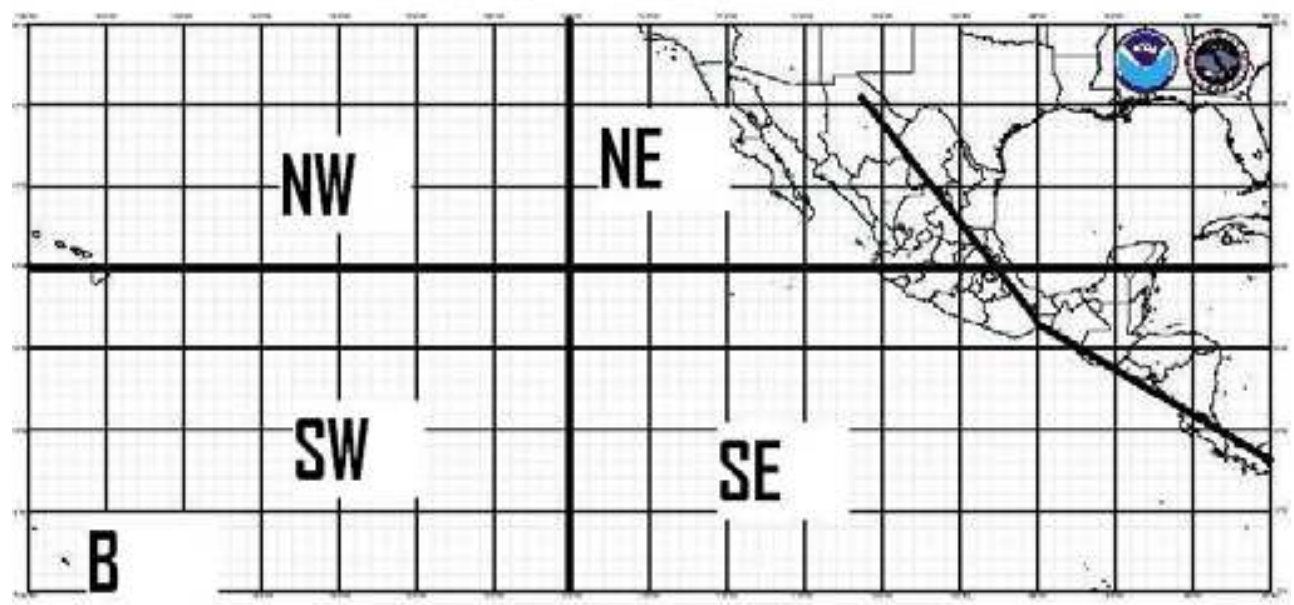

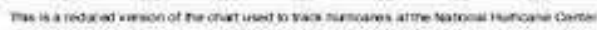

Fig. 1. The maps of a) the Atlantic Ocean Basin ( $\mathrm{G}=$ Gulf, $\mathrm{C}=$ Caribbean, $\mathrm{W}(\mathrm{E})=\mathrm{West}$ (East) Atlantic), and the b) Pacific Ocean Basin (NW = Northwest, NE = Northeast, $\mathrm{SW}=$ Southwest, and $\mathrm{SE}=$ Southeast) used in this study and provided by the National Hurricane Center. The heavy lines represent the boundaries between sub-basins used in this study. Their boundaries are outlined in section $2 \mathrm{~b}$ and L $\mathrm{L00}$. The diagonal line across Mexico represents a dividing line between the Atlantic and Pacific Basins. 


\subsection{El Niño and Pacific decadal oscillation definitions}

As in Lupo et al. (2008) and references therein, the Japan Meteorological Agency (JMA) ENSO Index was used in this study. A list of El Niño (EN), La Niña (LN), and Neutral (NEU) years used here are displayed in Table 1. In addition to consulting LJ00 or Lupo et al. (2008), a more detailed description of the $\mathbb{M A}$ ENSO Index can be found on the COAPS website (http:/ / coaps.fsu.edu/ jma.shtml). In summary, the index uses long-term running mean sea surface temperature (SST) anomalies from the Niño 3 and 3.4 regions in the central and eastern tropical Pacific (e.g., Pielke and Landsea 1999). The SST anomaly thresholds used to define $\mathrm{EN}$ years are those greater than $+0.5^{\circ} \mathrm{C}$, less than $-0.5^{\circ} \mathrm{C}$ for $\mathrm{LN}$ years, and NEU otherwise. The JMA ENSO criterion defined the El Niño year as beginning on 1 October of the previous year. This definition, however, was modified for the Northern Hemisphere following LJO0 so that the El Niño year coincided with the Atlantic and East Pacific TC seasons. No modification was needed for the SH.

The PDO (also known as the North Pacific Oscillation [NPO] in some studies) is a 50 to 70 year oscillation recently described (e.g., Minobe 1997; Mantua et al. 1997) within the eastern Pacific Ocean basin. As defined by Gershanov and Barnett (1998), the positive (warm) phase of the PDO (Fig. 2) is characterized by an anomalously deep Aleutian Low. Cold western and central north Pacific waters, warm eastern Pacific coastal waters, and warm tropical Pacific waters also characterize this phase of the PDO. Following Lupo et al. (2008) this phase is referred to as PDO1. The reverse conditions characterize the negative (cool) phase of PDO (Fig. 2) and these conditions are referred to as PDO2 (e.g., LJ00; Lupo et al. 2008). Each PDO period, or era, is defined using calendar years (see Table 2) and this information can also be found in Gershanov and Barnett (1998) and Lupo et al. (2007, 2008).

\begin{tabular}{|c|c|c|}
\hline La Niña (LN) & Neutral (NEU) & El Niño (EN) \\
\hline 1938 & 1939 & 1940 \\
\hline 1942 & 1941 & 1951 \\
\hline 1944 & 1943 & 1957 \\
\hline 1949 & $1945-1948$ & 1963 \\
\hline $1954-1956$ & 1950 & 1965 \\
\hline 1964 & $1952-1953$ & 1969 \\
\hline 1967 & $1958-1962$ & 1972 \\
\hline $1970-1971$ & 1966 & 1976 \\
\hline $1973-1975$ & 1968 & 1982 \\
\hline 1988 & $1977-1981$ & $1986-1987$ \\
\hline $1998-1999$ & $1983-1985$ & 1991 \\
\hline 2007 & $1989-1990$ & 2002 \\
\hline & $1992-1996$ & 2006 \\
\hline & $2000-2001$ & 2009 \\
\hline
\end{tabular}

Table 1. A list of years examined in this study separated by ENSO phase. The current year is not officially classified yet. 


\begin{tabular}{|c|c|}
\hline PDO Phase & Period of Record \\
\hline & \\
\hline Phase 1 & $1933-1946$ \\
\hline Phase 2 & $1947-1976$ \\
\hline Phase 1 & $1997-1998$ \\
\hline Phase 2 & $1999-$ present \\
\hline
\end{tabular}

Table 2. Phases of the Pacific Decadal Oscillation (PDO) since 1933.

Landsea (1993), Goldenberg and Shapiro (1996), Gray et al. (1997), and Landsea et al. (1999) have demonstrated that hurricane activity is tied to changes in the long-term pressure patterns in the Atlantic Ocean basin (e.g., the North Atlantic Oscillation, or NAO). Deser et al. (2004) also demonstrate that sea level pressure and other background variables (e.g., wind shear) have displayed interdecadal variations, and Vimont and Kossin (2007) correlate these to Atlantic tropical cyclone activity. LJOO and Lupo et al. (2008) found that the influence of the PDO was manifested by changes in the ENSO-related variability, specifically, that there was little or no ENSO related variability during PDO2, and significantly fewer and less (more and more) intense hurricanes during EN (LN) years during PDO1. As stated by $\mathrm{LJ00}$, the NAO-related variations in TC activity can make interpretation of PDO-related hurricane variability more difficult given the overlap in the time scales between the PDO and long-term variations in the NAO. Many studies have speculated that these decade-to-decade variations in Atlantic hurricanes are forced by a combination of both. In the East Pacific Ocean, there were more TCs during EN years, and these in general were more intense (Lupo et al. 2008). As was found in the Atlantic, the PDO variability in the Pacific Ocean was primarily found in PDO1, while there was little or no variability in PDO2. Thus, ENSO is the main driver of interannual TC activity as demonstrated by many studies, and since PDO can be shown to modulate ENSO behavior, the focus here will be on these teleconnections.

\section{Global tropical cyclone activity and trends up to the present}

As stated in Lupo et al. (2008), there have been some changes to the information related to some storms due to reanalysis in the original data sets used by $\mathrm{L} \mathrm{LO}$, and it is possible this would impact more than just the Atlantic region. Additionally, the latest TC seasons have been added for the Atlantic and East Pacific since the original publication of LJ00 or Lupo et al. (2008), and tropical storm information is included here. The analysis of TC activity in the other global ocean basins is new, including that of the South Atlantic.

\subsection{Atlantic tropical cyclone activity: $1938-2009$}

The data set used here for the Atlantic Ocean has the longest period of record at 72 years. Since 1938, there have been a total of 752 TCs, including 326 tropical storms, and 165, 78, 86, 70 , and 27 category $1-5$ hurricanes (Table 3a, 4). During the 2000-2009 tropical cyclone seasons, there were 72 Atlantic hurricanes (Table 3a), which means that the years since the LJ00 study were the most active during the $1938-2009$ record. However, the Atlantic TC seasons since 1995 have been relatively active. During the six year period from 1995 - 2000, there were 49 hurricanes ( 81 TCs), while during the years from $2001-2006$, there were been 47 hurricanes (94 TCs), in spite of the fact that 15 hurricanes occurred during the 2005 season. Two other six-year periods were compared to these two recent eras and both of 
these earlier periods occurred before the satellite era. In particular, 43 (37) hurricanes and 62 (74) TCs occurred from 1884-1889 (1932-1937). Thus, it would be reasonable to consider the activity of these pre-satellite era periods as comparable to the modern eras, since it is very likely that some TCs were missed during the pre-satellite era.

Additionally, during the 2000 - 2009, there were 35 intense hurricane (category $3-5$ ), which represented $49 \%$ of all storms (Table 3a). This compares with the LJ00 study in which $42 \%$ of all storms were intense during the previous 62 years. This indicates an increase in the ratio of intense storms overall. The increased activity of the latest period, however, is similar to that of the number of intense storms for the 30-year period of 1940-69 (48\% - Table 3). Thus, as shown in Tables 3a and 4 for the entire 72-year record, the inclusion of the last ten years has not made any noteworthy change in the ratio of hurricane intensities for the overall Atlantic Ocean basin activity.

\section{Pacific Decadal Oscillation}

Positive (warm) phase (PDO1) Negative (cool) phase (PDO2)
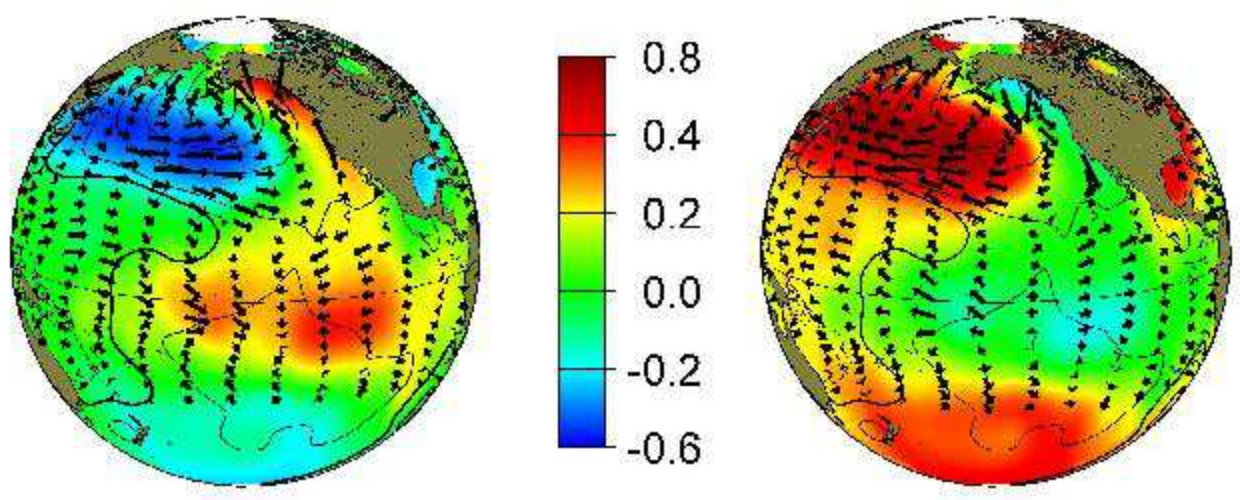

Fig. 2. The phases of the PDO as described in the text. SST anomalies are shown in color in accord with the scale shown. The arrows show anomalies in wind speed and direction. Reproduced with permission from the Joint Institute for the Study of Atmosphere and Ocean (JISAO - http:/ / jisao.w ashington.edu) at the University of Washington.

LJ00 reported that there were no statistically significant trends in the Atlantic Ocean basin hurricane activity. Adding the 2000-2009 hurricane and tropical storm occurrences does not result in any change in the trends for the overall occurrence of category $1-5$ storms (Fig. 3a). Separating these by category demonstrates that the trends for category 2-5 storms were not statistically significant (not shown). The trend in tropical storms (Fig 3b) and category 1 hurricanes (not shown) show an increase stronger than that in Fig. 3a, which shows the overall trend for the total number of hurricanes (significant at the 99\% confidence level). Whether this upward trend in category one storms or tropical storms is real is clouded by two issues. The trend could be the result of 1) the problem of the "fortuitous" placement starting and ending points in a long time series (the recent activity could be the peak in a long-term oscillation), or 2) that the earlier part of the 72-year period was in the pre-satellite era and storms may have been undercounted. It is likely that both of these factors are contributing to the overall increase. Nonetheless, if the 1970-2009 period only was used, 
there was an increase in the occurrence of Atlantic basin tropical storms and category one hurricanes and the trends were also statistically significant (not shown) at the 95\% confidence level. However, an examination of Fig. 3 suggests significant interannual variability as found by LeO0 and Lupo et al. (2008).

\subsection{East Pacific tropical cyclone activity: $1970-2009$}

Including tropical storms, there were 656 East Pacific TC events included in the 40-year sample. This resulted in an average of 16.1 TCs per season (Table 3b, 5). This includes 298 tropical storms (7.3 per year) and 358 hurricanes (8.9 per year). As expected, the number of category 1 storms was the largest (125), and there were 166 intense storms (category 3-5), which represented $46.4 \%$ of the hurricane activity. This compares to $42.8 \%$ overall in the Atlantic Ocean basin overall.

a. Atlantic

\begin{tabular}{|c|c|c|c|c|c|}
\hline Category & $1940-69$ & $1970-89$ & $1990-99$ & $2000-09$ & All \\
\hline & & & & & \\
\hline TS & 3.7 & 4.3 & 4.6 & 7.7 & 4.5 \\
\hline Cat. 1,2 & 3.1 & 3.5 & 3.9 & 3.7 & 3.3 \\
\hline Cat. 3-5 & 2.9 & 1.7 & 2.5 & 3.5 & 2.5 \\
\hline Cat. 4,5 & 1.4 & 0.9 & 1.4 & 2.1 & 1.3 \\
\hline & & & & & \\
\hline Tot hur. & 6.0 & 5.1 & 6.4 & 7.2 & 5.8 \\
\hline TS+Hur. & 9.7 & 9.4 & 11.0 & 14.9 & 10.3 \\
\hline
\end{tabular}

b. East Pacific

\begin{tabular}{|c|c|c|c|c|}
\hline Category & $1970-89$ & $1990-99$ & $2000-09$ & All \\
\hline & & & & \\
\hline TS & 7.6 & 5.6 & 9.1 & 7.3 \\
\hline Cat. 1,2 & 5.2 & 4.5 & 4.4 & 4.6 \\
\hline Cat. 3-5 & 4.2 & 5.5 & 2.8 & 4.1 \\
\hline Cat. 4,5 & 2.1 & 3.9 & 1.8 & 2.4 \\
\hline & & & & \\
\hline Tot hur. & 9.3 & 10.0 & 7.2 & 8.8 \\
\hline TS+Hur. & 16.9 & 15.6 & 16.3 & 16.1 \\
\hline
\end{tabular}

c. West Pacific

\begin{tabular}{|c|c|c|c|c|c|}
\hline Category & $1940-69$ & $1970-89$ & $1990-99$ & $2000-09$ & All \\
\hline & & & & & \\
\hline TS & 7.2 & 10.0 & 10.3 & 10.4 & 8.9 \\
\hline Cat. 1,2 & 7.5 & 8.2 & 9.1 & 6.5 & 7.7 \\
\hline Cat. 3-5 & 10.4 & 7.8 & 9.0 & 9.5 & 9.1 \\
\hline Cat. 4,5 & 6.6 & 5.1 & 7.3 & 8.0 & 6.4 \\
\hline & & & & & \\
\hline Tot hur. & 17.8 & 16.0 & 18.1 & 16.0 & 16.8 \\
\hline TS+Hur. & 25.1 & 26.0 & 28.4 & 26.4 & 25.7 \\
\hline
\end{tabular}


d. North Indian

\begin{tabular}{|c|c|c|c|c|c|c|}
\hline Category & $1940-69$ & $1970-76$ & $1977-89$ & $1990-99$ & $2000-09$ & All \\
\hline Unknwn & 14.6 & 16.0 & N/A & N/A & N/ A & 14.9 \\
\hline TS & N/A & N/A & 3.7 & 2.9 & 2.9 & 3.4 \\
\hline Cat. 1,2 & N/A & N/A & 0.6 & 1.3 & 0.7 & 0.9 \\
\hline Cat. $3-5$ & N/A & N/A & 0.3 & 1.0 & 0.3 & 0.5 \\
\hline Cat. 4,5 & N/ A & N/A & 0.1 & 0.7 & 0.3 & 0.4 \\
\hline & & & & & & \\
\hline Tot hur. & N/A & N/A & 0.9 & 2.3 & 1.0 & 1.4 \\
\hline TS+Hur. & N/A & N/A & 4.6 & 5.2 & 4.9 & 4.8 \\
\hline
\end{tabular}

e. Southern Hemisphere

\begin{tabular}{|c|c|c|c|c|c|c|}
\hline Category & $1940-69$ & $1970-79$ & $1980-89$ & $1990-99$ & $2000-09$ & All \\
\hline & & & & & & \\
\hline Unknwn & 27.8 & 30.2 & N/ A & N/ A & N/ A & 28.5 \\
\hline TS & N/A & N/A & 14.6 & 12.8 & 13.0 & 13.5 \\
\hline Cat. 1,2 & N/ A & N/A & 8.0 & 7.8 & 5.6 & 7.0 \\
\hline Cat. $3-5$ & N/A & N/A & 5.0 & 7.3 & 7.2 & 6.6 \\
\hline Cat. 4,5 & N/A & N/A & 1.6 & 4.8 & 4.5 & 3.8 \\
\hline Tot hur. & N/A & N/A & 13.0 & 15.1 & 12.9 & 13.5 \\
\hline TS+Hur. & N/A & N/A & 27.6 & 27.9 & 25.8 & 27.0 \\
\hline
\end{tabular}

Table 3. The mean annual number of hurricane and tropical storm (TS) events within the a) Atlantic, b) East Pacific, c) West Pacific, d) North Indian, and e) Southern Hemisphere Basins over decadal time periods corresponding with similar studies. Hurricanes are stratified by weak hurricanes (Cat. 1 and 2), intense hurricanes (Cat. 3, 4, and 5), and Cat. $4+$ Cat. 5. Categories are based on the Saffir-Simpson scale.

\begin{tabular}{|c|c|c|c|c|c|c|c|c|}
\hline & All & TS & Cat 1 & Cat 2 & Cat 3 & Cat 4 & Cat 5 & Thur $_{\text {hur }}$ \\
\hline LN & 10.9 & 5.0 & 1.9 & 1.4 & 1.1 & 1.1 & 0.4 & 5.9 \\
\hline NEU & 10.8 & 4.4 & 2.6 & 1.0 & 1.3 & 1.1 & 0.4 & 6.4 \\
\hline EN & 8.8 & 4.1 & 2.1 & 0.9 & 1.1 & 0.6 & 0.1 & 4.7 \\
\hline Total & 10.3 & 4.6 & 2.3 & 1.1 & 1.2 & 1.0 & 0.4 & 5.8 \\
\hline
\end{tabular}

Table 4. The average annual occurrence of Atlantic Ocean Basin tropical storms and hurricanes versus El Niño / La Niña phase for each Saffir-Simpson category from 1938 - 2009.

\begin{tabular}{|c|c|c|c|c|c|c|c|c|}
\hline Phase & All & TS & Cat 1 & Cat 2 & Cat 3 & Cat 4 & Cat 5 & Thur \\
\hline LN & 15.1 & 7.3 & 3.0 & 1.7 & 1.6 & 1.4 & 0.1 & 7.8 \\
\hline NEU & 16.4 & 7.2 & 3.3 & 1.7 & 1.5 & 2.6 & 0.1 & 9.1 \\
\hline EN & 17.6 & 8.0 & 2.9 & 1.7 & 2.1 & 2.2 & 0.7 & 9.6 \\
\hline Tot & 16.1 & 7.3 & 3.0 & 1.7 & 1.7 & 2.2 & 0.3 & 8.8 \\
\hline
\end{tabular}

Table 5. As in Table 4, except for the East Pacific from 1970 - 2009. 
The overall trend demonstrates that there was a decrease in the number of East Pacific Ocean hurricanes (Fig. 4a), but an upward trend in the number of tropical storms (Fig. 4b). However, neither trend was statistically significant. The overall trend in hurricane numbers was opposite to the Atlantic basin where there was a statistically significant increase in activity over the same period. If the two basins are combined for the period, there was no statistically significant trend upward or downward. It is noted here that trend lines shown in Fig. 3a and Fig. 4a are simple linear best fit (regression) models. The two time series (from 1970 for the Atlantic region) correlated to each other negatively (correlation coefficient of 0.385 , significant at the $90 \%$ confidence level), and this will likely be explained by the interannual variability in hurricane activity for both basins being opposite one another as discussed below. The correlation between the two increases to -0.405 when all TCs are included in Figs. 3 and 4. An examination of the trends in each East Pacific hurricane category would demonstrate that only the category 3 (5) storms showed a significant downward (upward) trend, while the rest of the categories showed no significant trend.

\section{Atlantic tropical cyclone occurrence}

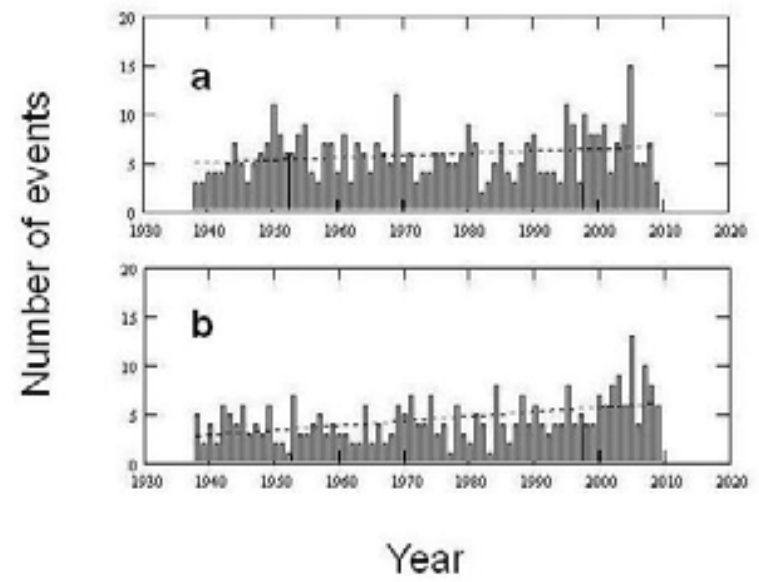

Fig. 3. The annual frequency of hurricane occurrence in the Atlantic Ocean basin for a) all categories, and b) tropical storms for the period $1938-2009$. The dashed line is the linear trend line.

\subsection{West Pacific tropical cyclone activity: $1945-2009$}

The West Pacific Ocean data set used here was the second longest period of record of the global ocean basins where TCs form at 65 years. This basin is arguably the most active of the global ocean basins. Since 1945, there have been a total of 1694 TCs, including 588 tropical storms, and 312, 195, 179, 257, and 163 category $1-5$ hurricanes (Table 3c, 6). This represents a mean of 16.9 hurricanes and 25.7 total TCs per year in the West Pacific. In this region, the proportion of intense hurricanes (599) is greatest at 54\% of the total number of hurricanes (1106). Of these intense hurricanes, Category 4 storms represented the second largest total (257) of hurricanes in the entire sample, which represented $23.2 \%$ of all TCs. It should not be surprising that this basin should contain the greatest fraction of intense hurricanes given 
that some of the warmest ocean temperatures in the world are found within the basin (e.g., Hurrell et al. 1995).

\section{East Pacific tropical cyclone occurrence}

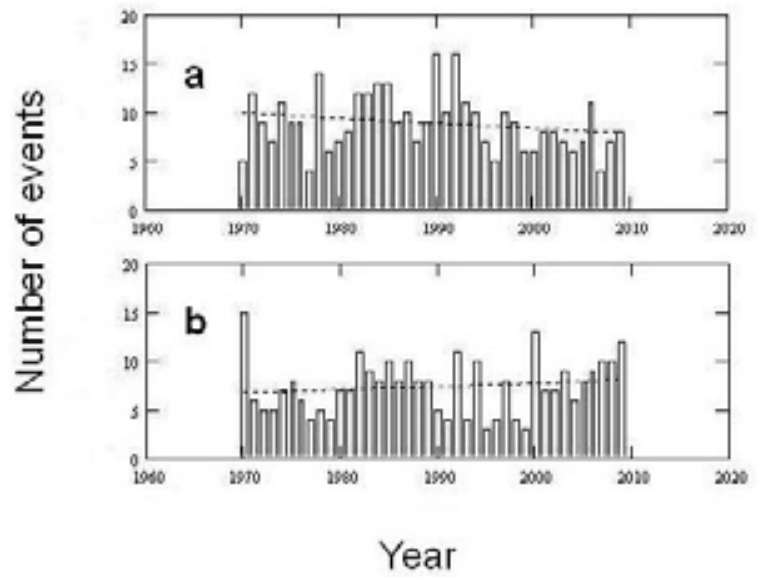

Fig. 4. As in Fig. 3, except for the East Pacific Ocean Basin and the years 1970 - 2009.

\begin{tabular}{|c|c|c|c|c|c|c|c|c|}
\hline Phase & All & TS & Cat 1 & Cat 2 & Cat 3 & Cat 4 & Cat 5 & Thur $_{\text {hur }}$ \\
\hline & & & & & & & & \\
\hline LN & 25.5 & 9.6 & 5.0 & 3.0 & 2.5 & 3.3 & 2.2 & 15.9 \\
\hline NEU & 26.4 & 9.2 & 5.1 & 3.1 & 2.7 & 3.9 & 2.4 & 17.2 \\
\hline EN & 25.9 & 8.2 & 3.9 & 2.7 & 3.2 & 4.8 & 3.1 & 17.7 \\
\hline & & & & & & & & \\
\hline Tot & 25.7 & 8.9 & 4.7 & 3.0 & 2.7 & 3.9 & 2.5 & 16.8 \\
\hline
\end{tabular}

Table 6. As in Table 4, except for the West Pacific from 1945 - 2009.

As in the East Pacific Ocean Basin, the number of hurricanes since 1945 were showing a slight downward trend (Fig. 5a), but this trend is not statistically significant. Table 3c demonstrates that within this trend, the number of category 1 and 2 storms were higher during the $1970-1990$ s, while the number of intense hurricanes were higher during the 1940 's - 1969 and during the most recent decade. This suggested there may be variability within this basin on the interdecadal time scale and this will be investigated in section 4 . The number of tropical storms increased throughout the period (Fig. 5b), and this trend was shown to be statistically significant (at the 99\% confidence level) as well. This result is similar to the result found for the Atlantic Ocean basin, but this is also likely to be the result of better monitoring for these storms. Recall the satellite era began in the mid-1960's and Table 3c suggests that there has been no significant trend in West Pacific tropical storm activity since 1970. Lastly, West Pacific Ocean basin hurricane activity correlates positively to East Pacific hurricane activity (0.375) and this correlation is significant at the $90 \%$ confidence level. Like the East Pacific, this basin also correlates negatively to Atlantic Ocean hurricane activity, but the correlation is not statistically significant. 


\subsection{North Indian tropical cyclone activity: 1977 - 2009}

In this region, tropical storm activity has been recorded since 1945 but storms were not assigned an intensity rating regularly until 1977. This is a similar situation to that of the East Pacific where TCs were classified as tropical storms or category 1 hurricanes from 1949 to 1969. During the early period there was an average of 14.9 TCs per year in the North Indian Ocean Basin. From 1977 - 2009 there were only 161 North Indian TCs found in this basin or an average of 4.8 events per year (Tables $3 \mathrm{~d}, 7$ ). In the next section, it will be demonstrated that most of this change took place in the Bay of Bengal region (Eastern half of the study region). This is likely to be the result of a change in the monitoring of these storms, in that during the earlier period, it is possible that tropical depressions and tropical waves were also counted. The North Indian Ocean Basin TCs include 116 tropical storms (3.4 per year) and 45 hurricanes (1.4 per year). As expected, the number of category 1 storms was the largest (23), and there were only 17 intense storms (category 3-5), which represented only $37.8 \%$ of the hurricane activity, or an average of 1 intense hurricane every two years. This is the low est proportion of intense hurricanes of the NH Ocean basins.

The overall trend since 1977 demonstrates that there was little or no trend in either hurricanes or the number of tropical storms within the North Indian Ocean Basin (Fig. 6). There was little trend in the pre-1977 overall numbers as well (not shown). Additionally, there is little or no correlation between TC occurrence in the Northern Indian Ocean and the other NH Basins. However, the lack of a trend does not mean there are no interannual or interdecadal variations to describe and these will be discussed below.

\section{West Pacific tropical cyclone occurrence}

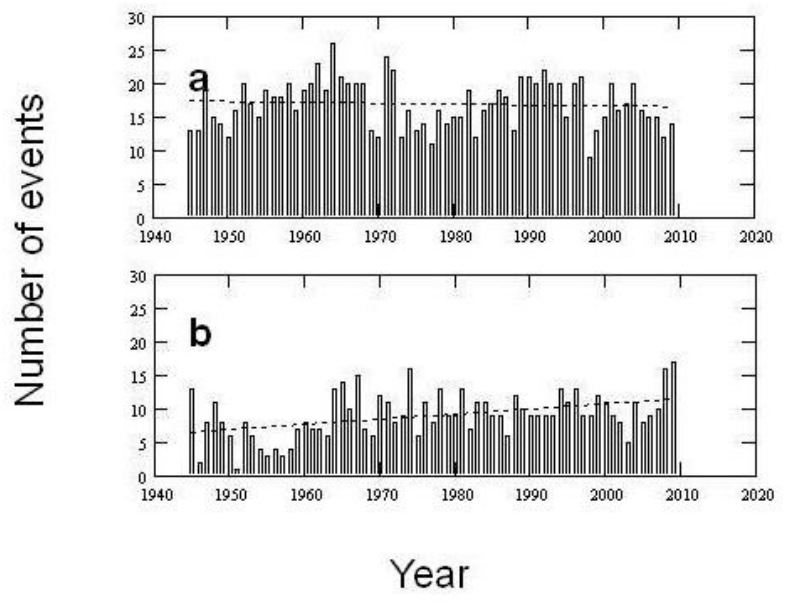

Fig. 5. As in Fig. 3, except for the West Pacific Ocean Basin and the years 1945 - 2009.

\subsection{Southern Hemisphere tropical cyclone activity: 1980 - 2010}

In this region, tropical storm activity has also been recorded since 1945 but storms were not assigned an intensity rating regularly until 1980. In the SH, the tropical season peaks during the $\mathrm{NH}$ winter and spring. Since the tropical season does not follow the calendar here, the tropical year 2010 actually began 1 July, 2009 and ended June 30, 2010. During the period 
before 1980, there was an average of 28.5 TCs per year in the SH. From $1980-2010$ there were $837 \mathrm{SH}$ TCs found for an average of 27.0 events per year (Tables 3e, 8). Thus, there was not a large change between the means of the pre- and post- 1980 era. Additionally, this is only one more TC than that of the West Pacific Ocean basin only on an annual basis.

\begin{tabular}{|c|c|c|c|c|c|c|c|c|}
\hline Phase & All & TS & Cat 1 & Cat 2 & Cat 3 & Cat 4 & Cat 5 & Thur \\
\hline & & & & & & & & \\
\hline LN & $5.5 / 14.8$ & 3.0 & 1.0 & 0.3 & 0.8 & 0.3 & 0.3 & 2.5 \\
\hline NEU & $4.8 / 15.4$ & 3.4 & 0.8 & 0.1 & 0.1 & 0.2 & 0.0 & 1.3 \\
\hline EN & $4.9 / 14.0$ & 4.0 & 0.3 & 0.1 & 0.0 & 0.4 & 0.1 & 0.9 \\
\hline & & & & & & & & \\
\hline Tot & $4.8 / 14.9$ & 3.4 & 0.7 & 0.2 & 0.2 & 0.3 & 0.1 & 1.4 \\
\hline
\end{tabular}

Table 7. As in Table 4, except for the North Indian Ocean from 1977 - 2009 (all - second number is pre-1977 era).

\section{North Indian tropical cyclone occurrence}

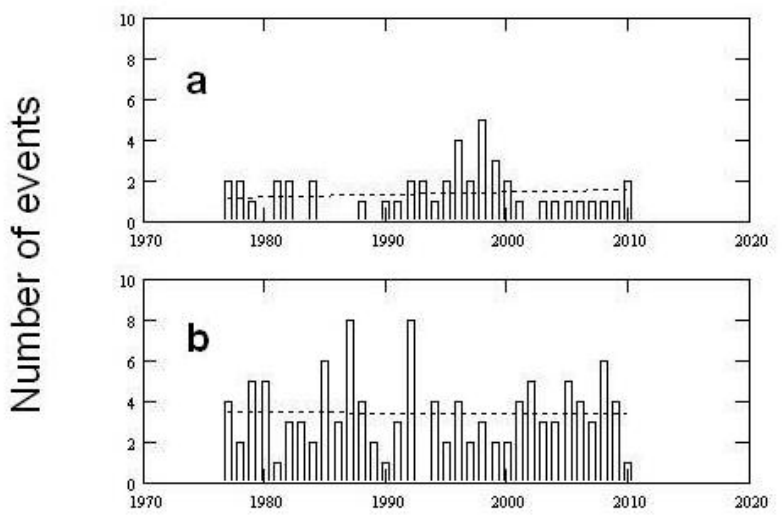

Year

Fig. 6. As in Fig. 3, except for the Northern Indian Ocean Basin and the years 1977 - 2010.

\begin{tabular}{|c|c|c|c|c|c|c|c|c|}
\hline Phase & All & TS & Cat 1 & Cat 2 & Cat 3 & Cat 4 & Cat 5 & Thur \\
\hline & & & & & & & & \\
\hline LN & $29.3 / 30.3$ & 13.3 & 5.5 & 2.5 & 3.3 & 4.3 & 0.5 & 16.0 \\
\hline NEU & $26.9 / 25.8$ & 13.9 & 4.8 & 1.8 & 3.9 & 2.8 & 0.5 & 12.9 \\
\hline EN & $26.1 / 31.1$ & 12.3 & 5.1 & 2.1 & 2.3 & 3.3 & 1.0 & 13.8 \\
\hline & & & & & & & & \\
\hline Tot & $27.0 / 28.5$ & 13.5 & 5.0 & 2.0 & 2.8 & 3.1 & 0.6 & 13.5 \\
\hline
\end{tabular}

Table 8. The mean number of SH tropical storms and hurricanes separated by ENSO phase and intensity (Saffir - Simpson scale) from 1980 - 2010 (except all - the second number is the pre-1980 era). 
In this region, it is likely that better records were kept following 1980, and if tropical depressions are added in post-1980, the means are nearly identical (not shown). In the SH, there were 417 tropical storms (13.5 per year) and 420 hurricanes (13.5 per year). Like the West Pacific Ocean basin, category 4 storms constituted the second largest number of hurricanes (cyclones) after category 1 storms with 97 total events, and this represented $23.1 \%$ of all hurricanes. The percentage of intense storms (category 3-5, 204 cyclones) was $48.6 \%$, which was similar to that of the Atlantic region.

The overall trend since 1980 demonstrates that there was little or no trend in either hurricanes (cyclones) or the number of tropical storms within the SH (Fig. 7), which is similar to the North Indian Ocean Basin. There was little trend in the pre-1980 overall numbers as well (not shown). Additionally, there is little or no correlation between TC occurrences in the $\mathrm{SH}$ basins with those in the $\mathrm{NH}$ basins, except for those in the Northern Indian Ocean basin. However, this correlation did not rise to the level of statistical significance. As will be shown later, there are interannual or interdecadal variations and these will be discussed below.

\section{Southern Hemisphere tropical cyclone occurrence}

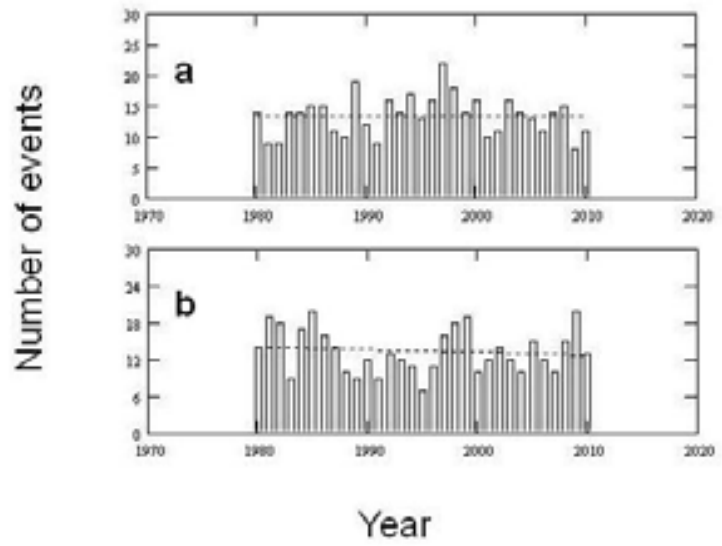

Fig. 7. As in Fig. 3, except for the Southern Hemisphere and the years 1980 - 2010.

\subsection{South Atlantic tropical cyclone activity: 1960 - 2010}

While there are very few instances of TC occurring in the South Atlantic because of cold sea surface temperatures and stronger tropospheric wind shears, there have nonetheless been occurrences worthy of note. The most famous event was Hurricane Catarina which occurred in March 2004, and is recognized as the only storm to become of hurricane strength in this basin (e.g. Reagan et al. 2005; McTaggart-Cowan et al. 2006). The most recent occurrence was a tropical storm (designated 90Q, or Tropical Storm Anita) documented by the National Aeronautics and Space Administration (NASA) during March 10-12, 2010 (http:/ / www.nasa.gov/ mission_pages/ hurricanes/ archives/ 2010/ h2010_90Q.html). There have been five other possible events, all tropical depressions or tropical storms, in this ocean basin occurring during March 1974, April 1991 (McAdie and Rappaport, 1991), January 2004, February, 2006, and January, 2009. There may be some question whether or not some 
of these reached tropical storm strength, however, there is no doubt that with better observational technology, there have been more possible tropical events observed during the last decade in this region than at any other time. The tropical season in this region would be primarily January to March, which would correspond to July through September in the North Atlantic. Also, given the small number of events, the interannual and interdecadal variability cannot be assessed.

\section{Interannual and interdecadal variability in tropical cyclones.}

Then, in order to identify the significant periodicities within the times series (e.g., Figs. 3 - 7), power spectra were constructed and analyzed. Fig. 8 displays the power spectrum analysis of the Atlantic Basin annual TC occurrence time series constructed using Fourier coefficients. Also shown in the Fig. 8 is the $95 \%$ confidence level against a continuum background of white or red noise (Wilks 2006). Not surprisingly, periods of significant variability emerge in the analysis. In Fig 8a (b), significant interannual and interdecadal variability is evident, and the time periods are at roughly 5,9 , and $24(3,5,12$, and 18) years for Atlantic hurricanes (TC). The higher frequency variability is consistent with the time scale of ENSO, while the low est frequency variations are suggested here to be representative of interdecadal PDO-related variability (Minobe, 2000). In addition, significant interdecadal variability at time periods of approximately 9 and 12-15 years are similar to that of Enfield and Mestas-Núñez (1999), Mestas-Núñez and Enfield (1999), or Birk et al. (2010), and attributed to the PDO or PDO - ENSO related interactions. Similar variability was found in the other ocean basins (not shown), especially the NH Pacific Ocean basins which have longer time series available.

\subsection{Atlantic Ocean Basin variability}

In Table 4, there were more TCs in LN and NEU years in the 72-year dataset as well as in the number of hurricanes and intense hurricanes than in EN years as in $\mathrm{LJO0}$ and Lupo et al. (2008). None of these results rise to the level of statistical significance when testing the means only. Additionally, if these results are tested as a probability distribution (Fig. 9), and using the chi-square test (e.g., Neter et al. 1988) also reveals no statistically differences between the distribution in ENSO years. However, the distributions were not the same at the $95 \%$ confidence level either.

In examining differences within the Atlantic Ocean Basin by sub-region (Fig. 1 and Table 9) reveals that there were some differences in which regions were more active. While the West Atlantic showed little difference between individual years in the number of TCs, the Caribbean was more (less) active in $\mathrm{LN}$ (EN) years. But, these differences in TC activity do not rise to the level of statistical significance. Also, if the annual distribution is examined (Fig. 10), there were some differences in the duration of the TC season as shown in LJ00 and Lupo et al. (2008). The nominal TC season in the Atlantic is recognized as 1 June to 30 November. This can be demonstrated by a certain level of observed TC activity occurring during a particular month. Here, 0.6 events per year was chosen as this represents a frequency greater than once every two years for a particular month. In Fig. 10, the TC seasons for the total sample and neutral years were 1 June to 30 November. However, in LN years, the season typically begins later (July), exhibits a stronger peak, and is more active later into the season (November). However, EN years tended to be more active earlier (June), and less active later, and these results were found by LJ00 and Lupo et al. (2008). 

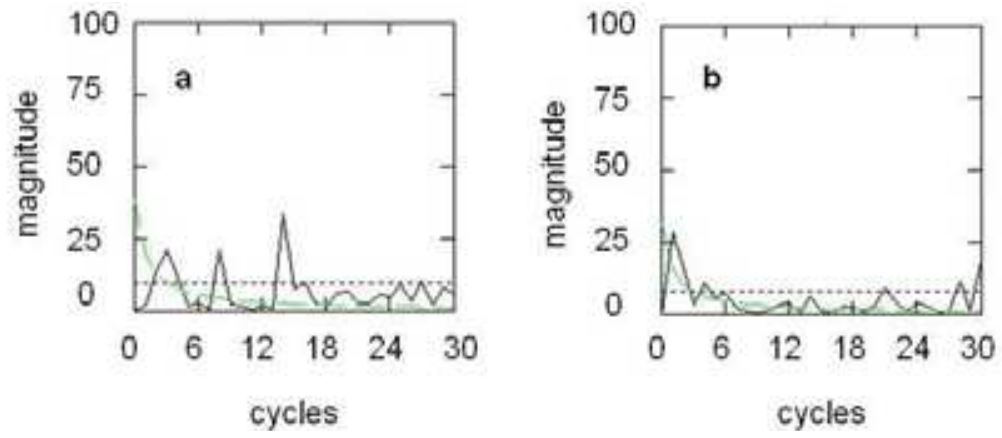

Fig. 8. The fourier power spectra for Atlantic Basin a) hurricane, and b) total tropical cyclone frequencies. The abscissa is the number of cycles during the 72 year period, and the ordinate is the magnitude of the fourier coefficients. The dotted (dashed) line is the $95 \%$ confidence level assuming a white (red) power spectrum (e.g., Wilks, 2006).

a) Total sample

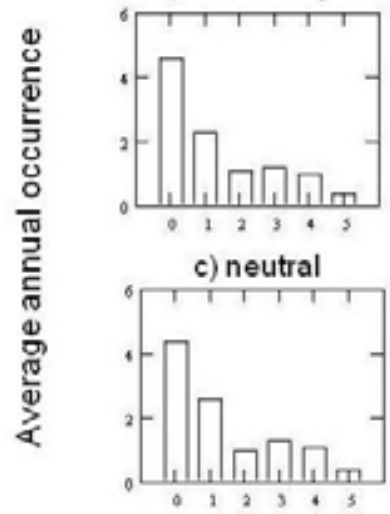

b) La Nina

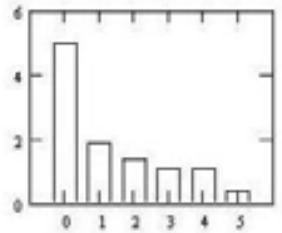

d) ElNino

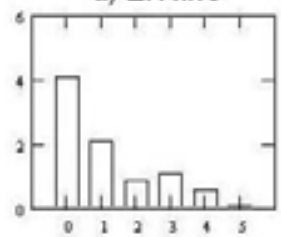

Category - Saffir-Simpson Scale

Fig. 9. Histograms of the average annual hurricane frequency in the Atlantic separated by category (0 is tropical storm) for a) the total sample (1938-2009), b) La Niña years, c) neutral years, and d) El Niño years.

\begin{tabular}{|c|c|c|c|c|c|}
\hline & All & Crbn & Gulf & W Atl & E Atl \\
\hline & & & & & \\
\hline LN & 10.9 & 2.1 & 2.3 & 5.0 & 1.4 \\
\hline NEU & 10.8 & 1.7 & 2.2 & 5.1 & 1.8 \\
\hline EN & 8.8 & 0.8 & 1.8 & 5.2 & 1.2 \\
\hline & & & & & \\
\hline Total & 10.3 & 1.6 & 2.1 & 5.1 & 1.5 \\
\hline
\end{tabular}

Table 9. The average annual occurrence of Atlantic hurricanes and tropical storms by subocean basin as stratified by ENSO phase. The regions are the Caribbean (Crbn), Gulf of Mexico (Gulf), West Atlantic (W Atl), and East Atlantic (E Atl) sub-basins. 
While many of the differences above did not rise to the level of statistical significance, these results are examined then by separating into PDO phase (Table 2) following LJ00 and Lupo et al. (2008) then some interesting results emerge. The TC activity during PDO2 (Table 10a) displayed little ENSO-related variability. Also, the variability as measured by the standard deviations during these years was also larger (not shown). Thus, predictability during these years would be more difficult. During PDO1 (Table 10b), there was stronger ENSO-related variability than found in the dataset overall. LJO0 and Lupo et al. (2008) found that the number of hurricanes was significantly greater in $\mathrm{LN}$ years than during EN years and this was significant at the $90 \%$ confidence interval, and this is true here as well. The greatest disparity was found in intense hurricanes, and during PDO1 LN years there were three times as many intense hurricanes.

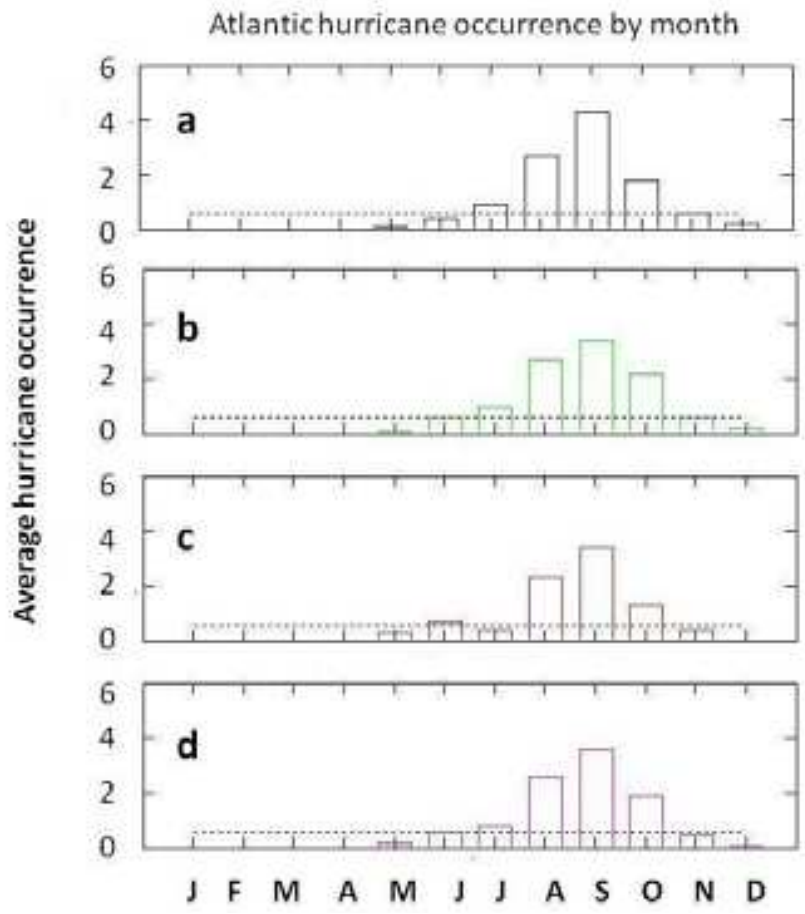

Fig. 10. The annual mean tropical cyclone occurrence by month for a) La Niña, b) neutral, c) El Niño, and d) total sample for the Atlantic Ocean Basin. The dotted line represents 0.6 TC events per month.

If these results were separated by sub-basin (not shown), the West Atlantic showed little ENSO related variability in either PDO phase. However, during PDO1, the other sub-basins were more active in $\mathrm{LN}$ years and in the Caribbean the difference was significant at the $90 \%$ confidence level. The seasonal differences are also magnified during PDO1 years (not shown). During LN (EN) years, the season is July through November (July through October). Finally, there is some differences in the length of season among each of the subbasins. The west Atlantic has the longest season, while in the East Atlantic is basically active during August and September and this shows little variability by ENSO or PDO year. 
a. $\quad \mathrm{PDO} 2$

\begin{tabular}{|c|c|c|c|c|c|c|c|c|}
\hline & All & TS & Cat 1 & Cat 2 & Cat 3 & Cat 4 & Cat 5 & Thur \\
\hline & & & & & & & & \\
\hline LN & 11.0 & 4.9 & 1.9 & 1.3 & 1.2 & 1.2 & 0.4 & 6.0 \\
\hline NEU & 12.1 & 4.9 & 2.6 & 0.8 & 1.8 & 1.3 & 0.7 & 7.2 \\
\hline EN & 9.8 & 4.3 & 2.1 & 1.1 & 1.4 & 0.7 & 0.2 & 5.5 \\
\hline & & & & & & & & \\
\hline Total & 11.1 & 4.8 & 2.3 & 1.0 & 1.5 & 1.1 & 0.5 & 6.4 \\
\hline
\end{tabular}

b. PDO1

\begin{tabular}{|c|c|c|c|c|c|c|c|c|}
\hline & All & TS & Cat 1 & Cat 2 & Cat 3 & Cat 4 & Cat 5 & T hur \\
\hline & & & & & & & & \\
\hline LN & 11.0 & 5.2 & 1.8 & 1.8 & 0.8 & 0.8 & 0.6 & 5.8 \\
\hline NEU & 9.7 & 4.1 & 2.6 & 1.1 & 0.9 & 0.9 & 0.3 & 5.7 \\
\hline EN & 7.2 & 3.8 & 2.0 & 0.5 & 0.5 & 0.3 & 0.0 & 3.3 \\
\hline & & & & & & & & \\
\hline Total & 9.4 & 4.2 & 2.3 & 1.1 & 0.8 & 0.7 & 0.3 & 5.2 \\
\hline
\end{tabular}

Table 10. The average annual occurrence of Atlantic tropical cyclones stratified by ENSO phase and Category (Saffir-Simpson scale) during a) PDO2 (1947 - 1976, 1999-present), and b) PDO1 (1938-46, 1977-98).

\subsection{East Pacific Ocean variability}

A breakdown by ENSO phase (Table 5) indicates that there is some interannual variability in East Pacific region TC activity. Traditionally, May is the first month that significant TC activity begins in the East Pacific. In this study, August was the most active month with 165 total TC's occurring over the 40 year climatology (4 tropical cyclones per year), and by November, this region is relatively inactive. Thus, the East Pacific season was roughly one calendar month ahead of the Atlantic season, a result similar to Davis et al. (1984) and Schultz (2007). By geographic region (Table 11), the southeast part of the East Pacific was the most active, and $84 \%$ of the TC occurrences happened within this region. Only five TC, including two hurricanes occurred in the northwest region.

\begin{tabular}{|l|l|l|l|l|l|}
\hline Phase & NE & SE & SW & NW & Tot \\
\hline & & & & & \\
\hline LN & 1.0 & 12.3 & 1.4 & 0.3 & 15.1 \\
\hline NEU & 1.0 & 12.8 & 2.4 & 0.1 & 16.4 \\
\hline EN & 0.5 & 13.7 & 3.4 & 0.0 & 17.6 \\
\hline & & & & & \\
\hline Tot & 0.9 & 12.7 & 2.4 & 0.1 & 16.4 \\
\hline
\end{tabular}

Table 11. As in Table 9, except for the East Pacific basin geographic region (along $20^{\circ} \mathrm{N}$ and $\left.125^{\circ} \mathrm{W}\right)$.

During EN years, there were more TC in the East Pacific (Table 5), and this included more storms reaching hurricane strength, especially intense hurricanes, in this region than in LN 
years. This might be expected as the waters in the East Pacific are warmer during EN years. While the greater overall frequency of EN year TC is not statistically significant, it is opposite of the ENSO variability in the Atlantic Ocean basin. When separating by PDO phase (Table 12), it can be shown that there was little overall ENSO variability in PDO2 years, while the ENSO variability was accentuated in PDO1 years (two more hurricanes and four more TC overall during EN years) as it was in the Atlantic region (LJ00), except here EN years were more active (a result significant at the $90 \%$ confidence level). Additionally, there was more TC activity in PDO1 years (e.g. Lupo et al., 2008). These were years characterized by stronger warm ENSO SST anomalies located closer to the Americas (see Lupo et al. 2007), or over the East Pacific region, especially the southeast portion of our basin of study. This provided the rationale for the breakdown of the East Pacific Region into sub-basins.

a. $\mathrm{PDO} 2$

\begin{tabular}{|c|c|c|c|c|c|c|c|c|}
\hline & All & TS & Cat 1 & Cat 2 & Cat 3 & Cat 4 & Cat 5 & Thur \\
\hline & & & & & & & & \\
\hline LN & 15.4 & 7.7 & 3.1 & 1.9 & 1.4 & 1.1 & 0.1 & 7.7 \\
\hline NEU & 15.7 & 8.8 & 3.0 & 2.0 & 0.7 & 1.2 & 0.0 & 6.8 \\
\hline EN & 16.8 & 7.8 & 2.0 & 1.8 & 2.2 & 2.2 & 0.8 & 9.0 \\
\hline & & & & & & & & \\
\hline Total & 15.9 & 8.1 & 2.8 & 1.9 & 1.4 & 1.4 & 0.3 & 7.8 \\
\hline
\end{tabular}

b. PDO1

\begin{tabular}{|c|c|c|c|c|c|c|c|c|}
\hline & All & TS & Cat 1 & Cat 2 & Cat 3 & Cat 4 & Cat 5 & Thur $_{\text {hur }}$ \\
\hline & & & & & & & & \\
\hline LN & 14.0 & 6.0 & 2.5 & 1.0 & 2.0 & 2.5 & 0.0 & 8.0 \\
\hline NEU & 16.7 & 6.6 & 3.4 & 1.5 & 1.9 & 3.1 & 0.1 & 10.1 \\
\hline EN & 18.4 & 8.2 & 3.8 & 1.6 & 2.0 & 2.2 & 0.6 & 10.2 \\
\hline & & & & & & & & \\
\hline Total & 16.8 & 6.9 & 3.4 & 1.5 & 1.9 & 2.9 & 0.2 & 9.9 \\
\hline
\end{tabular}

Table 12. As in Table 10, except for the East Pacific.

In order to determine if there were variations in the intensity of storms, LJO0 and Lupo et al. (2008) used histograms and compared their distributions, testing these for statistical significance. For the overall East Pacific sample here, there were no significant differences in the distributions (Fig. 11), even though the differences in the hurricane frequencies (Table 12) demonstrate that there were differences in the overall averages for the occurrence of intense storms. During PDO2 (there was little ENSO-related interannual variability), and PDO1 (EN years significantly more active), the results were different even if there were no statistically significant differences in the distributions (which can be inferred from Table 12). There were clearly more intense storms during EN years (5.2 versus 2.6 for $\mathrm{LN}$ ) for PDO2 years. However, the real substantive differences between hurricane occurrences in EN and LN years during PDO1 were the result of a greater number of weaker hurricanes and tropical storms. The PDO1 result is consistent with the results of Schultz (2007), who used a different methodology but found that during more active years, there were a greater 
number of weaker storms. This is, how ever, different from the Atlantic were LJ00 (and Lupo et al. 2008) found that there were more intense storms during $\mathrm{LN}$ years, especially in the PDO1 phase.

Comparing the length of the East Pacific season by examining the monthly occurrence (Fig. 12), shows that during EN years, TC activity is greatest from June through November, while in LN years, the season is one month shorter (primarily June - October). The seasonal variations in tropical storms versus hurricanes were similar overall. However, the seasonal peak in each ENSO phase occurred in different months. During EN years, the peak in tropical cyclone activity was clearly August, while in neutral years the peak was later (August / September), and earlier (July / August) in LN years. There was little difference in the ENSO-related seasonal cycles between the phases of the PDO here (not shown).

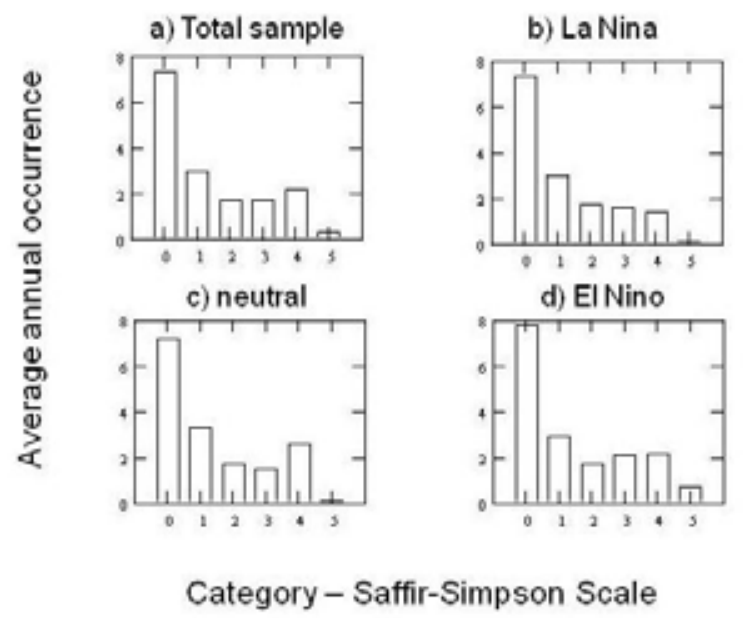

Fig. 11. As in Fig. 9 Except for the East Pacific

A breakdown of TC activity by geographic region (see Lupo et al., 2008) demonstrated that the southeast region was the most active, and varied similarly to that of the total sample discussed above. The northeast region, however, was relatively more active in $\mathrm{LN}$ and NEU years, while the southwest region was more active in EN and NEU years (Table 11). During the EN years, this reflects the fact that warmer SSTs were located over the East Pacific formation regions (see Lupo et al. 2007), especially in the southern sectors. While nearly all of the intense hurricanes were in the southwest and southeast regions, neither region had a significantly higher proportion of category 4 and 5 storms. Only one hurricane which formed north of $20^{\circ} \mathrm{N}$ achieved category 3 status. A separation of these data by phase of the PDO (not shown) would reveal that the ENSO variability described above is independent of the phase of the PDO in the East Pacific.

\subsection{West Pacific Ocean variability}

As shown in section 3, West Pacific Ocean TC activity correlated positively with that in the East Pacific. Unlike the results of section 4.1 and 4.2, Table 6 shows that indicates that there is little ENSO related variability in West Pacific region TC activity overall. This would agree with the results of Chan (1985), Wu and Lau (1992), Lander (1994), Wang and Chan, (2002), 
and Chan (2007, 2009). Traditionally, in this basin it has been recognized that TC activity is possible throughout the year, however, the $\mathrm{NH}$ spring (fall) are times where this basin is minimally (maximally) active. In this basin, August and September were the most active months with 663 total TC's occurring over the 65 year climatology (about 5 TCs in each month per year). January through March in this region is relatively inactive using 0.6 storms per year as the benchmark for defining an active month. By geographic region (Table 13), the southwest part of the West Pacific (dividing along $20^{\circ} \mathrm{N}$ latitude and $140^{\circ}$ E Longitude) was the most active, but this region accounted for only $46 \%$ of the West Pacific TC occurrences. The southeast part accounted for $32 \%$, while the northeast and northwest regions accounted for $11 \%$ each of the remaining TC occurrences.

\section{East Pacific hurricane occurrence by month}

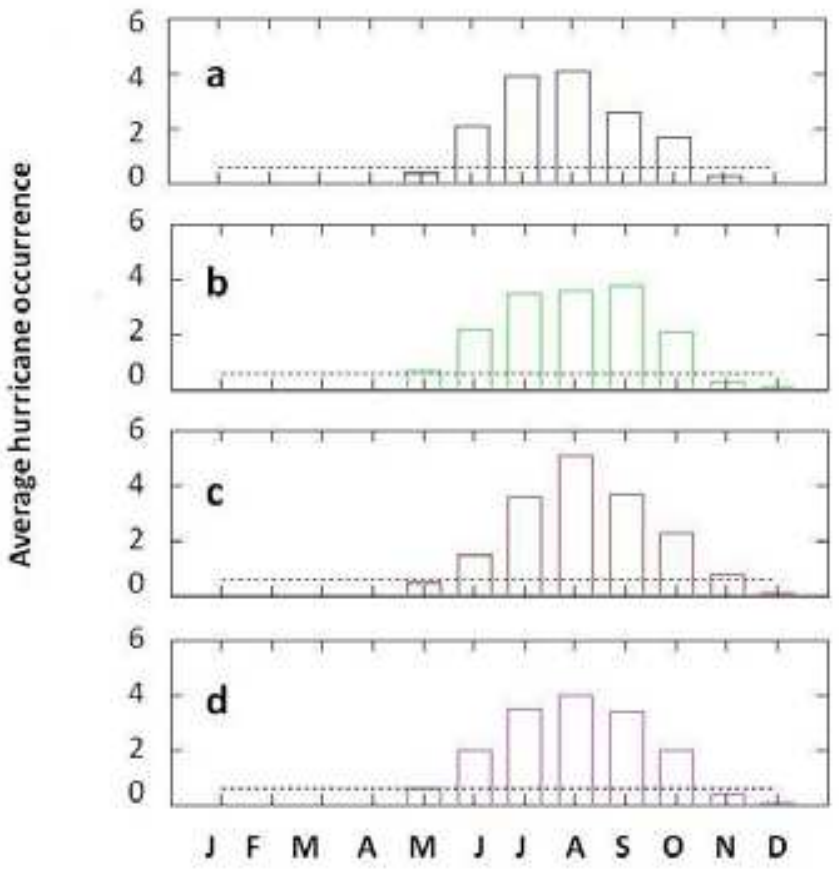

Fig. 12. As in Fig. 10 except for the East Pacific.

\begin{tabular}{|c|c|c|c|c|c|}
\hline Phase & NE & SE & SW & NW & Tot \\
\hline & & & & & \\
\hline LN & 3.3 & 5.1 & 13.1 & 3.5 & 25.5 \\
\hline NEU & 3.0 & 8.2 & 12.0 & 3.0 & 26.4 \\
\hline EN & 1.7 & 11.6 & 10.4 & 2.1 & 25.9 \\
\hline & & & & & \\
\hline Tot & 2.7 & 8.2 & 11.7 & 2.9 & 25.7 \\
\hline
\end{tabular}

Table 13. As in Table 9, except for the West Pacific by geographic region (along $20^{\circ} \mathrm{N}$ and $\left.140^{\circ} \mathrm{E}\right)$. 
While there was little difference in the overall TC numbers in this basin, a more detailed look would find some significant variability within the West Pacific Basin. Similar to the results of the East Pacific, there were more storms reaching hurricane strength, and especially more intense TCs (11.1 versus 8.0) during EN years (Table 6), while there were more weaker storms during $\mathrm{LN}$ years. The intense hurricane difference was significant at the $90 \%$ confidence level. As in the East Pacific, the expanded pool of warmer waters in the tropical Pacific overall may be part of the reason for this result. When separating by PDO phase (Table 14), the results are similar to the East Pacific and Atlantic. There was little overall ENSO variability in PDO2 years, while there was strong ENSO variability in PDO1 years. In PDO2 years, the ENSO variability mimicked that described above, however, during PDO1 years, there was very strong ENSO related variability, which was significant at nearly the $95 \%$ confidence level. There were roughly six more TCs during PDO1 EN years. This difference was found primarily among intense storms where there were 12 (6) intense storms during EN (LN) years, and this result is significant at the $98 \%$ confidence level.

a. $\quad \mathrm{PDO} 2$

\begin{tabular}{|c|c|c|c|c|c|c|c|c|}
\hline & All & TS & Cat 1 & Cat 2 & Cat 3 & Cat 4 & Cat 5 & Thur \\
\hline & & & & & & & & \\
\hline LN & 26.2 & 9.5 & 5.2 & 3.2 & 2.7 & 3.2 & 2.4 & 16.7 \\
\hline NEU & 26.1 & 8.3 & 4.7 & 2.9 & 3.2 & 4.2 & 2.8 & 17.8 \\
\hline EN & 25.1 & 8.3 & 3.6 & 1.9 & 3.1 & 5.5 & 2.7 & 16.8 \\
\hline & & & & & & & & \\
\hline Total & 25.9 & 8.7 & 4.6 & 2.8 & 3.0 & 4.2 & 2.7 & 17.2 \\
\hline
\end{tabular}

b. PDO1

\begin{tabular}{|c|c|c|c|c|c|c|c|c|}
\hline & All & TS & Cat 1 & Cat 2 & Cat 3 & Cat 4 & Cat 5 & T $_{\text {hur }}$ \\
\hline & & & & & & & & \\
\hline LN & 21.5 & 10.5 & 3.5 & 1.5 & 1.0 & 4.0 & 1.0 & 11.0 \\
\hline NEU & 26.6 & 10.1 & 5.5 & 3.4 & 2.2 & 3.5 & 1.9 & 16.5 \\
\hline EN & 27.4 & 8.0 & 4.4 & 4.2 & 3.4 & 3.4 & 4.0 & 19.4 \\
\hline & & & & & & & & \\
\hline Total & 26.4 & 9.7 & 5.1 & 3.4 & 2.3 & 3.5 & 2.3 & 16.7 \\
\hline
\end{tabular}

Table 14. As in Table 10, except for West Pacific Ocean.

In order to confirm further the variations in the intensity of TCs, here we compare histograms and their distributions, testing these for statistical significance (Fig. 13). In the overall results, the distribution for $\mathrm{LN}$ years was different from that of the distribution in EN years, but this result was not significant at the $90 \%$ confidence level. It does rise to the level of statistical significance (90\%) if only PDO1 years were used (not shown).

Comparing the length of the West Pacific season by examining the monthly occurrence (Fig. 14), shows that during EN years, the TC season is longest extending from March - January, while in LN and NEU years, the season is two months shorter (primarily April - December). The seasonal peak in each ENSO phase occurred in August and September just as in the total sample. During EN years, the peak in TC activity was clearly August, while in neutral 
years the peak was later (August / September), and earlier (July / August) in LN years. There was little difference in the ENSO-related seasonal cycles for PDO2 years, but interestingly, in PDO1 EN seasons were one month shorter. However, PDO1 LN years were considerably shorter than that of other years (not shown) extending from only June December, and with a pronounced September peak not found in any other subsample.

A breakdown of TC cyclone activity by geographic region demonstrated that the southwest region was the most active (Table 13), and but the interannual and interdecadal variations were opposite that of the total sample. In particular, there were more TCs in LN years in the overall sample and during PDO2, and little TC variability during PDO1. As pointed out by others, the region of maximum activity changes as ENSO phase changes. During LN years, the southeast region is much less active, while the other three basins are more active. This may be partly due to the fact that there are cooler waters in the tropical eastern Pacific (see Lupo et al. 2007). Thus, the southeast region of the West Pacific basin and the southwest region of the East Pacific are relatively inactive confining Pacific Ocean activity overall closer to the continental areas during LN years. During EN years, the tropics across the entire Pacific are active, while the northern basins are less active. These results are also consistent with Zuki and Lupo (2008) whose study was performed within the southwest basin of this study.

a) Total sample

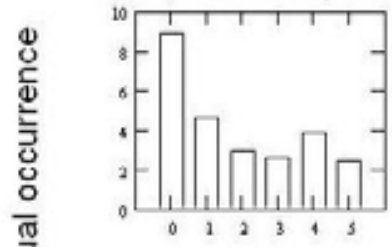

c) neutral

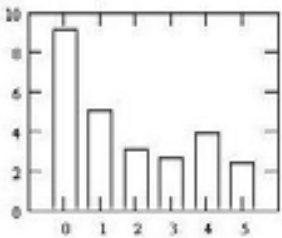

b) La Nina

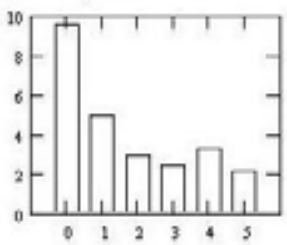

d) ElNino

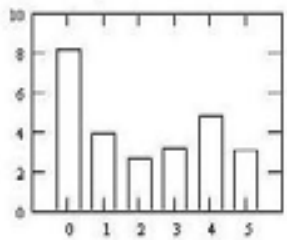

Category - Saffir-Simpson Scale

Fig. 13. As in Fig. 9 except for the West Pacific Ocean Basin.

As in the East Pacific, nearly all of the intense hurricanes were in the southwest and southeast regions, and neither region had a significantly higher proportion of category 4 and 5 storms. Of the 599 TCs which were intense storms only 59 TCs (10\%) formed north of $20^{\circ}$ $\mathrm{N}$. As the sample is limited to category $4 \mathrm{TCs}$, the number of storms in the northern two quadrants was only $5 \%$, and only four $(0.6 \%)$ TCs which were rated category 5 formed north of $20^{\circ} \mathrm{N}$. This is consistent with the results above that demonstrate that northern areas are less active in EN years, and TCs are less intense in $\mathrm{LN}$ years. 
West Pacific hurricane occurrence by month

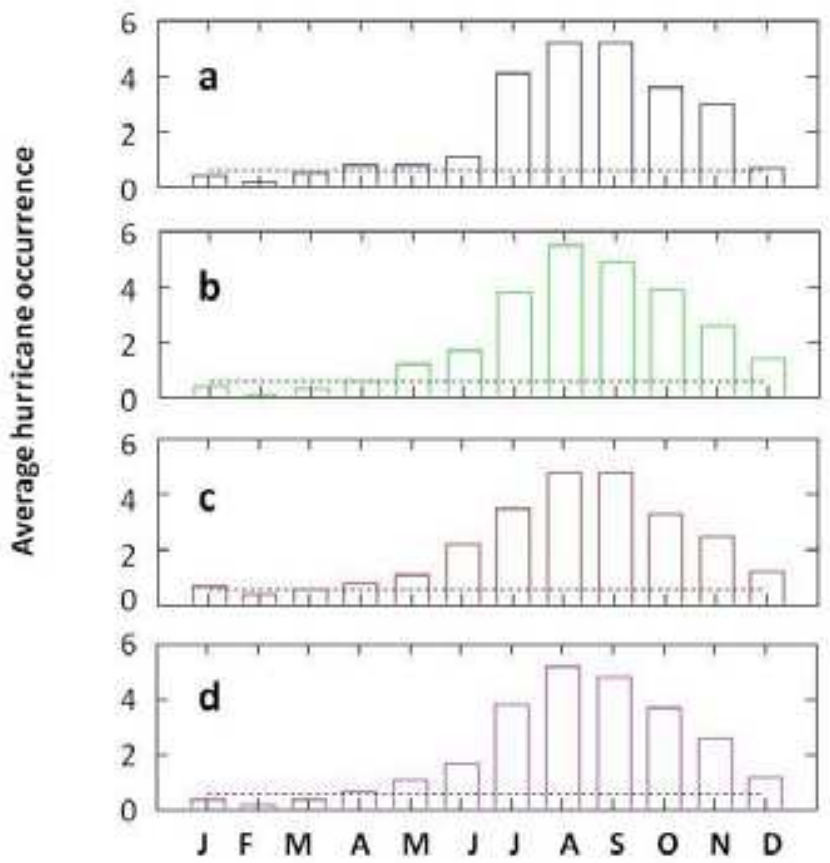

Fig. 14. As in Fig. 10 except for the West Pacific Ocean Basin.

\subsection{Northern Indian Ocean variability}

In section 3.4, it was shown that the data set in this region is only reliable after 1977. While this is fortuitous and coincides with an abrupt shift to PDO1 (Table 2), the result is that there is only a small sample of PDO2 TCs available, and, thus, any conclusions regarding interdecadal variability may be suspect. However, ENSO variability in the TC occurrences was significant at the $95 \%$ confidence level in the power spectra analysis (not shown) and there was significant variability at the 16 year period in the hurricane (cyclone locally) occurrences.

As shown in section 3, Northern Indian Ocean TC activity did not correlate with that of any other NH basin. Table 7 shows that the ENSO variability results in maybe one more TC per year in $\mathrm{LN}$ years, however, this basin has less activity than the other $\mathrm{NH}$ basins. In this basin, it has been recognized that TC activity maximizes at two particular times, late spring and fall with a summer minimum in TC activity (e.g., $\mathrm{Ng}$ and Chan, 2010). October and November are the most active months with 76 total TC's occurring over the 33 year climatology (about $1 \mathrm{TC}$ in each month per year). February, March, July, and August are the two inactive periods in this basin. This is likely related to the semi-annual passage of the Inter-tropical Convergence Zone (ITCZ) through this region (Hurrell et al., 1995) similar to that of the TC season in Malaysia (Zuki and Lupo, 2008). The passage of the ITCZ through the region would provide favorable atmospheric conditions for the generation of TCs.

Separating this region into west and east regions (Table 15), the east part of the North Indian Ocean (dividing along $75^{\circ}$ E Longitude) was the more active, accounting for about $75 \%$ of 
the North Indian TC occurrences. In section 3.4, it was speculated that the counting of tropical depressions and tropical waves likely provided for the severe over-count for TCs in this basin and this is especially true in the eastern half. There was almost no ENSO related variability in the east half, but in the west half, the variability was stronger with double the number of TCs in a LN years during the current era.

\begin{tabular}{|c|c|c|c|}
\hline Phase & West Indian & East Indian & Total \\
\hline & & & \\
\hline LN & $2.3 / 2.5$ & $3.8 / 12.2$ & $5.5 / 14.8$ \\
\hline NEU & $1.4 / 1.8$ & $3.4 / 13.6$ & $4.8 / 15.4$ \\
\hline EN & $1.0 / 2.7$ & $3.9 / 11.3$ & $4.9 / 14.0$ \\
\hline & & & \\
\hline Tot & $1.4 / 2.3$ & $3.5 / 12.6$ & $4.8 / 14.9$ \\
\hline
\end{tabular}

Table 15. As in Table 9, except for the North Indian Ocean by geographic region (along $75^{\circ}$ E) (second number is pre-1977 era).

An examination of the ENSO related variability in the North Indian region would reveal differences in the intensity of storms as well. While the results here were not similar to those of the West Pacific overall, there were similarities to the activity in the South China Sea (see Zuki and Lupo, 2008). More storms reached hurricane strength (2.5 to 1.0), and more intense TCs (1.4 versus 0.5 ) during LN years (Table 7), than during EN years. The intense hurricane difference was significant at the $95 \%$ confidence level. When separating by PDO phase (Table 16), the results are similar to the total sample for PDO1 years, while there was little variability in the small sample of PDO2 years. In order to further examine the variations in the intensity of storms, here we compare histograms and their distributions, testing these for statistical significance (Fig. 15). In the overall results, the distribution for La Niña years was different from that of the distribution in EN years, but this result did not rise to significance at the $90 \%$ confidence level.

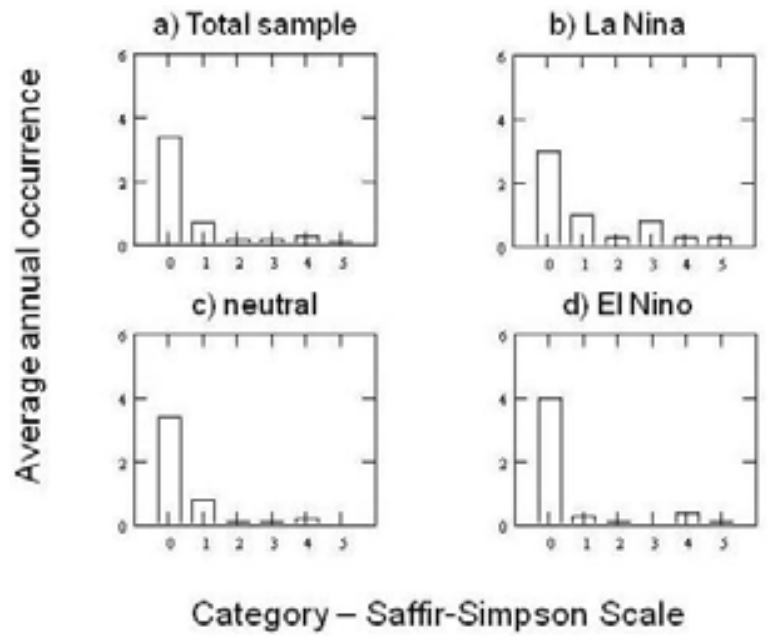

Fig. 15. As in Fig. 9, except for the Northern Indian Ocean. 
Comparing the length of the North Indian season by examining the monthly occurrence (Fig. 16), shows that during LN years, the TC season can be defined as May and June, and then again in October and November. In NEU years, the season is defined as May, and then October to December, while in EN years the TC season is basically May and November. The yearly maximum in each ENSO phase occurred in the late fall. During EN years, the peak in TC activity was clearly November, while in NEU and LN years the peak was October and November. There was little difference in the ENSO-related seasonal cycles for PDO1 years. However, for PDO2 years, the sample is similar to that of the total sample but the sample size is probably too small as of yet to comment on differences.

a. $\quad \mathrm{PDO} 2$

\begin{tabular}{|c|c|c|c|c|c|c|c|c|}
\hline & All & TS & Cat 1 & Cat 2 & Cat 3 & Cat 4 & Cat 5 & Thur \\
\hline & & & & & & & & \\
\hline LN & 4.5 & 2.5 & 0.5 & 0.0 & 0.5 & 0.5 & 0.5 & 2.0 \\
\hline NEU & 5.0 & 3.8 & 0.8 & 0.0 & 0.0 & 0.3 & 0.0 & 1.2 \\
\hline EN & 5.0 & 4.3 & 0.3 & 0.0 & 0.0 & 0.3 & 0.0 & 0.7 \\
\hline & & & & & & & & \\
\hline Total & 4.9 & 3.7 & 0.6 & 0.0 & 0.1 & 4.2 & 0.1 & 17.2 \\
\hline
\end{tabular}

b. PDO1

\begin{tabular}{|c|c|c|c|c|c|c|c|c|}
\hline & All & TS & Cat 1 & Cat 2 & Cat 3 & Cat 4 & Cat 5 & T hur \\
\hline & & & & & & & & \\
\hline LN & 6.5 & 3.5 & 1.5 & 0.5 & 1.0 & 0.0 & 0.0 & 3.0 \\
\hline NEU & 4.7 & 3.3 & 0.8 & 0.2 & 0.2 & 0.2 & 0.0 & 1.4 \\
\hline EN & 4.8 & 3.8 & 0.2 & 0.2 & 0.0 & 0.4 & 0.2 & 1.0 \\
\hline & & & & & & & & \\
\hline Total & 4.9 & 3.4 & 0.7 & 0.2 & 0.2 & 0.2 & 0.1 & 1.4 \\
\hline
\end{tabular}

Table 16. As in Table 10, except for the North Indian Ocean.

A breakdown of TC activity by geographic region demonstrated that the eastern region was the most active (Table 15), but there was little interannual and interdecadal variation. In the western half, there were more TCs in LN years in the overall sample and during PDO1, but little TC variability during PDO2. This difference between PDO1 and PDO2 activity is similar to that of all the other $\mathrm{NH}$ basins.

In the Northern Indian Ocean, there were only 17 intense hurricanes (cyclones), and many of these were in the eastern half (13) of the basin which represents roughly $75 \%$ of the total. Thus, the proportion of intense TCs in each basin is comparable to that of the total sample. Thus, the threat of an intense storm developing is similar in each half of the Northern Indian Ocean.

\subsection{Southern Hemisphere variability}

As shown above, there was a slight, but not statistically significant downward trend in TC activity in this hemisphere. It was shown also that the data set in this region is only reliable after 1980. The variability in this hemisphere was impacted strongly by ENSO, especially in the Southwest Pacific where the South Pacific Convergence Zone (e.g., Vincent, 1994; Hurrell et al. 1995), in particular the tropical portion, can provide the seed disturbances for 


\section{Northern Indian hurricane occurrence by month}

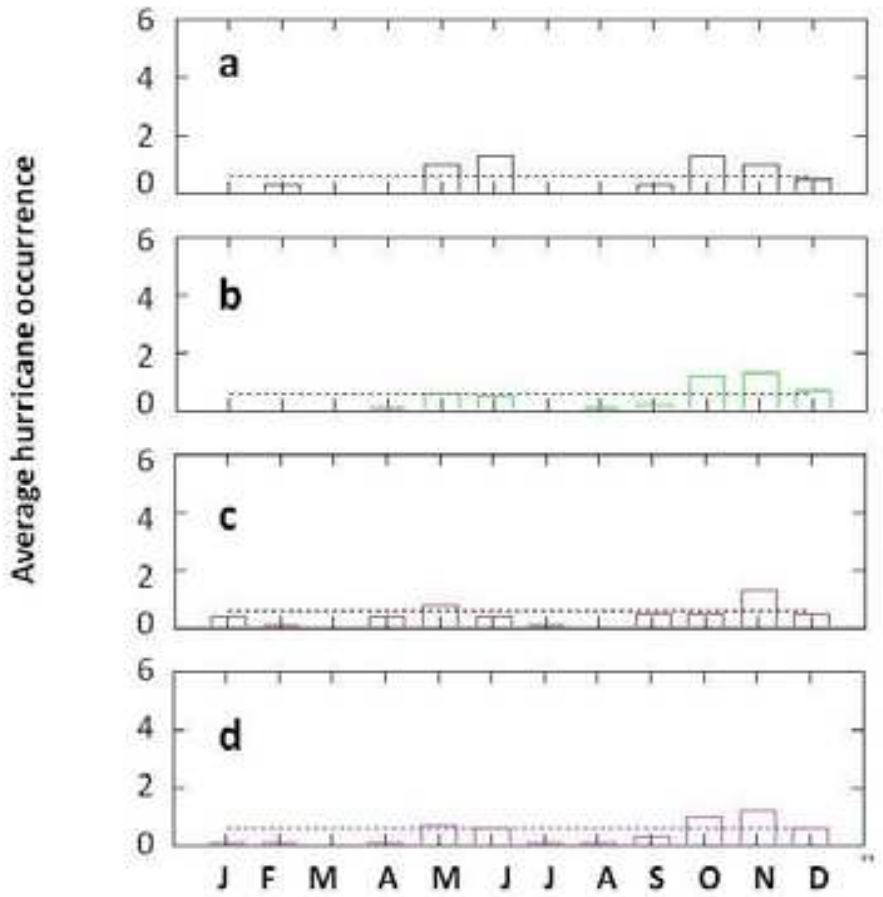

Fig. 16. As in Fig 10, except for the Northern Indian Ocean Basin.

TC formation. As was the case for the Northern Indian Ocean, any statements regarding interdecadal variability must be viewed with some caution in light of the fact that there was only 31 years worth of reliable records. Nonetheless, the power spectrum analysis (not shown) revealed statistically significant variability in the three, six and ten year periods in the SH. The SH was subdivided into four basins, the West and East Indian Ocean (along 75 $\mathrm{E}$ as in the $\mathrm{NH}$ ), and the Southwest and Southeast Pacific (divided along the dateline).

TC activity in the SH as a whole only positively correlated to activity in the North Indian Ocean, and this did not rise to the level of statistical significance. Table 8 shows that during $\mathrm{LN}$ years there was three (two) more TCs (hurricanes) overall during the annual cycle. This is not statistically significant difference. In the period before 1980, there was little ENSO related variability found in the SH Basin. The annual cycle for this basin was described in section 3 , but the period of peak activity is clearly during the summer and early fall months of the SH (December - March). The winter months (June - August) constitute the inactive period in this basin.

Separating the Indian Ocean part of the $\mathrm{SH}$ basin into the west and east Indian regions (Table 17), demonstrates the west part of the South Indian Ocean (dividing along $75^{\circ} \mathrm{E}$ Longitude) was less active than the east part, but this difference is much smaller than the difference between the activity in the west and east North Indian Ocean Basin. In spite of the fact that the activity was three times as great in the Southern Indian as in the Northern, the ratio between the west and east was roughly two to three. 


\begin{tabular}{|c|c|c|c|c|c|}
\hline Phase & West Indian & East Indian & SW Pacific & SE Pacific & Total \\
\hline & & & & & \\
\hline LN & $7.3 / 8.2$ & $9.8 / 9.2$ & $7.0 / 10.5$ & $5.0 / 2.0$ & $29.3 / 29.5$ \\
\hline NEU & $6.4 / 8.6$ & $11.2 / 7.8$ & $6.3 / 7.2$ & $2.9 / 1.8$ & $26.9 / 25.8$ \\
\hline EN & $5.0 / 8.6$ & $12.6 / 10.7$ & $6.8 / 12.3$ & $2.8 / 1.6$ & $26.1 / 33.7$ \\
\hline & & & & & \\
\hline Tot & $6.1 / 8.5$ & $8.8 / 11.3$ & $6.4 / 9.3$ & $3.3 / 1.8$ & $27.0 / 28.5$ \\
\hline
\end{tabular}

Table 17. As in Table 9, except for the Southern Hemisphere (along 75 E, Indian, and along dateline in Pacific, second number represents pre-1980 era).

In the west South Indian Ocean, there was strong ENSO variability in that there was more TC events in LN years in the west Indian Ocean, a result significant at the $90 \%$ confidence level. There was also less ENSO variability in the Eastern half of the South Indian Ocean basin but with a slight tendency toward more events in EN years. The ENSO related variability in each half compared favorably to the ENSO related variability in the Northern Indian Ocean, and this likely accounted for the positive correlation between the $\mathrm{SH}$ as a whole and the North Indian Ocean basin (compare Table 15 and Table 17). In the Southwest Pacific, there was little ENSO related variability in TC occurrence, but in the Southeast Pacific, there were roughly two more TCs in LN years than in EN years, how ever, this result was not statistically significant.

An examination of the ENSO related variability in the $\mathrm{SH}$ region would reveal little difference in the intensity of TCs (Table 8, Fig. 17). This result is not similar to those in other regions, where there was a tendency for more intense storms in one phase or another of the ENSO cycle. The differences in the distributions in Fig. 17 did not show a difference in intensity either when tested using the Chi-square test. Even the number of intense hurricanes across each phase of ENSO was similar (52\% LN years versus $49 \%$ EN years). In the $\mathrm{SH}$ as a whole, up to the time of this study, there was little difference in the overall

a) Total sample

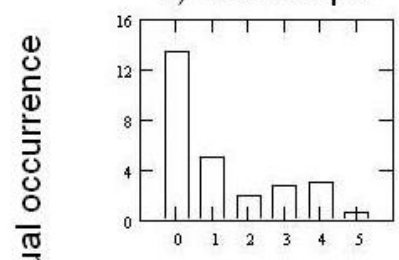

c) neutral

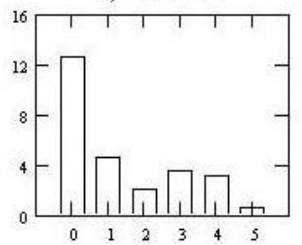

b) La Nina

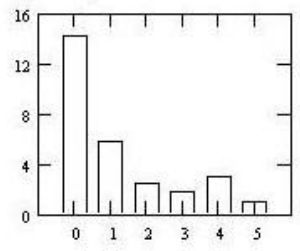

d) El Nino

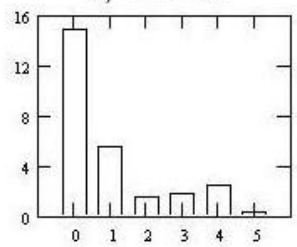

\section{Category - Saffir-Simpson Scale}

Fig. 17. As in Fig. 9, except for the Southern Hemisphere 
a. $\mathrm{PDO} 2$

\begin{tabular}{|c|c|c|c|c|c|c|c|c|}
\hline & All & TS & Cat 1 & Cat 2 & Cat 3 & Cat 4 & Cat 5 & Thur \\
\hline & & & & & & & & \\
\hline LN & 28.0 & 12.5 & 6.0 & 2.0 & 3.0 & 4.5 & 0.0 & 15.5 \\
\hline NEU & 25.0 & 13.8 & 3.6 & 0.8 & 2.3 & 3.2 & 1.2 & 11.2 \\
\hline EN & 25.3 & 11.6 & 4.0 & 1.0 & 2.7 & 4.7 & 1.3 & 13.6 \\
\hline & & & & & & & & \\
\hline Total & 25.6 & 13.0 & 4.2 & 1.1 & 2.5 & 3.8 & 1.0 & 12.6 \\
\hline
\end{tabular}

b. PDO1

\begin{tabular}{|c|c|c|c|c|c|c|c|c|}
\hline & All & TS & Cat 1 & Cat 2 & Cat 3 & Cat 4 & Cat 5 & T hur \\
\hline & & & & & & & & \\
\hline LN & 30.5 & 14.0 & 5.0 & 3.0 & 3.5 & 4.0 & 1.0 & 16.5 \\
\hline NEU & 27.7 & 14.0 & 5.3 & 2.3 & 3.2 & 2.7 & 0.2 & 13.8 \\
\hline EN & 26.6 & 12.8 & 5.8 & 2.8 & 2.0 & 2.4 & 0.8 & 13.8 \\
\hline & & & & & & & & \\
\hline Total & 27.8 & 13.7 & 5.4 & 2.5 & 3.0 & 2.8 & 0.5 & 14.1 \\
\hline
\end{tabular}

Table 18. As in Table 10, except for the Southern Hemisphere.

ENSO variability across each phase of the PDO (Table 18). This differed from all the NH basins where ENSO variability was enhanced in PDO1. However, a closer examination of Table 18 reveals that the number of intense hurricanes was much greater in the decade of the 2000's during ENSO years (64\% of all hurricanes, 34\% of TCs) versus ENSO years during the period 1980-1999 (37\% of all hurricanes, $20 \%$ of all TCs). While this may be a function of the small sample as of yet, given the interdecadal TC variability in the $\mathrm{NH}$, it would not be unexpected that there may be some interdecadal variations.

Comparing the length of the SH season by examining the monthly TC occurrence (Fig. 18), shows that the season can be defined as October to May overall (using 0.6 as the monthly guide), with the peak activity occurring during January and February. During EN and NEU years, the TC season could be defined similarly (but with a peak in February and January respectively), while in $\mathrm{LN}$ years, the season was shorter (November to April). However, in $\mathrm{LN}$ years, the most active months which constitute the broadest peak for any of the global ocean basins (January through March) are consistently more active (19) than the corresponding TC activity in EN and NEU years (16 and 17, respectively).

\section{Forecasting based on this work}

\subsection{Hindcasting the 2000-2005 seasons in the Atlantic and East Pacific}

Using the results of LJ00 and Lupo et al. 2008, forecasts have been made using this information. When forecasting (and hindcasting) TC activity in each basin for the upcoming season (Table 19) from 2000-2010 in a manner similar to that demonstrated by Lupo et al. (2008) (and LJ00 for 1999), it is shown that this work can be used to produce reliable forecasts. Since a forecast of the geographical distribution of storm genesis regions was given using their method, we evaluated the forecast using the same calculation used to determine $\chi^{2}$ for the statistical test (Neter et al. 1988). Thus, a lower score represents a better 
forecast, or shows an annual distribution closer to that of the climatological contingency forecast used by LN00. The years 2000 - 2005 presumed that the forecast of the ENSO phase was correct as LJ00 did for 1999. In the Atlantic, the poorest hindcast was that for the 2005 season, in which every basin was quite active and, thus, large errors in TC occurrence were recorded in each category. However, an active year did not guarantee a high score as the 2003 and 2004 seasons were similarly active, but the hindcast for the 2004 season was much better. In the East Pacific, the TC hindcasts were better overall and this is likely due to the fact that the southeast region TCs dominate the activity in this basin. Thus, the threshold for what constitutes a good forecast should probably be lower in this region, and several more years would be needed in order to establish a recommendation.

\section{Southern Hemisphere hurricane occurrence by month}

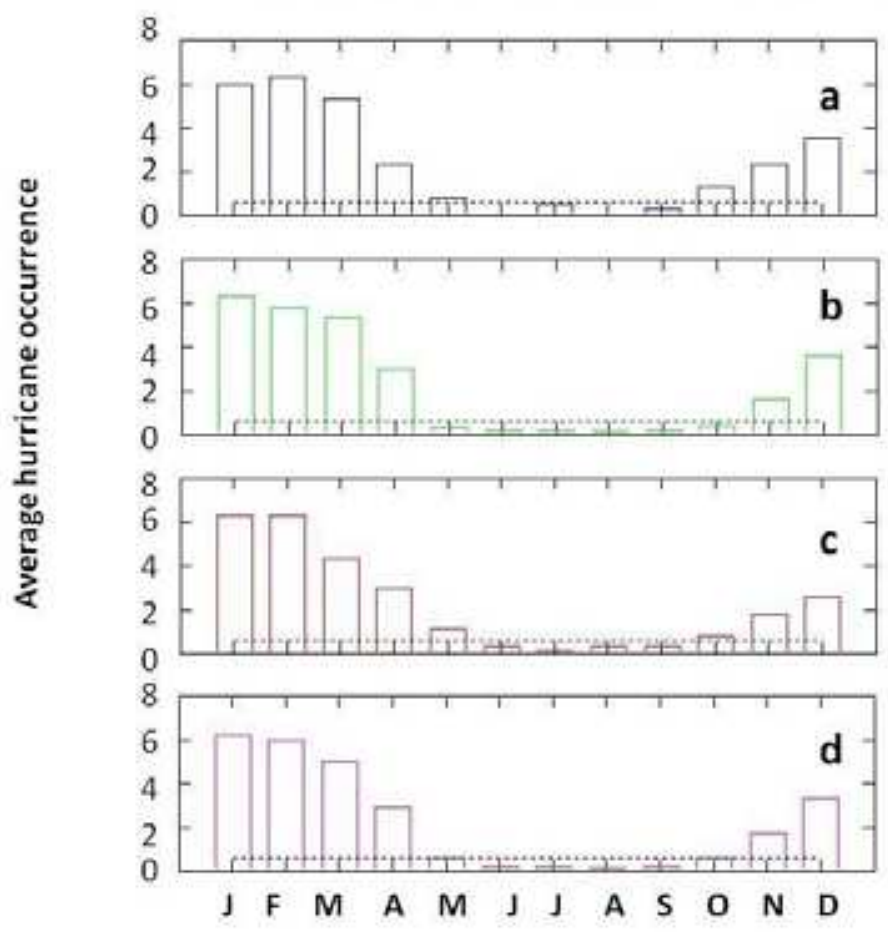

Fig. 18. As in Fig. 10, except for the Southern Hemisphere.

For each of these years, the ratio of tropical storms, weak hurricanes, and strong hurricanes was similar to what should be expected (see Tables 4 and 5). This would result in a forecast of a decreasing frequency in each category of stronger winds, except for PDO2 EN years in the East Pacific region where more strong TCs than weak storms are expected. In the Atlantic, only 2004 did not conform reasonably to the expected TC intensity distribution (we observed three weak hurricanes and six strong). In the Pacific and for each of these years, TC intensities were reasonably hindcast (not shown). 
Atlantic Region

\begin{tabular}{|c|c|c|c|c|c|c|c|}
\hline Year & & Carribean & Gulf & West. Atl & East Atl. & & Tot Score \\
\hline 2000 & & $1(1)$ & $3(1)$ & $8(3)$ & $3(1)$ & & $6(3.30)$ \\
\hline 2001 & & $4(2)$ & $2(0)$ & $8(3)$ & $1(1)$ & & $6(4.50)$ \\
\hline 2002 & & $2(0)$ & $3(1)$ & $6(1)$ & $1(1)$ & & $3(2.20)$ \\
\hline 2003 & & $1(1)$ & $6(4)$ & $4(1)$ & $5(3)$ & & $9(13.20)$ \\
\hline 2004 & & $1(1)$ & $2(0)$ & $6(1)$ & $5(3)$ & & $5(5.20)$ \\
\hline 2005 & & $7(5)$ & $6(4)$ & $11(6)$ & $4(2)$ & & $17(31.70)$ \\
\hline 2006 & & $1(1)$ & $1(1)$ & $7(2)$ & $1(1)$ & & $5(2.30)$ \\
\hline 2007 & & $2(0)$ & $4(2)$ & $7(2)$ & $2(0)$ & & $4(2.80)$ \\
\hline 2008 & & $4(2)$ & $1(1)$ & $3(2)$ & $3(1)$ & & $6(3.80)$ \\
\hline 2009 & & $1(0)$ & $1(1)$ & $4(1)$ & $3(2)$ & & $4(4.70)$ \\
\hline 2010 & & $5(2)$ & $1(1)$ & $7(2)$ & $6(4)$ & & $9(9.97)$ \\
\hline
\end{tabular}

East Pacific Region

\begin{tabular}{|c|c|c|c|c|c|c|c|}
\hline Year & & northeast & southeast & southwest & Northwest & & Tot Score \\
\hline 2000 & & $0(1)$ & $15(3)$ & $3(1)$ & $1(1)$ & & $6(3.25)$ \\
\hline 2001 & & $1(0)$ & $9(3)$ & $5(3)$ & $0(0)$ & & $6(5.25)$ \\
\hline 2002 & & $0(1)$ & $11(2)$ & $4(1)$ & $0(0)$ & & $4(1.64)$ \\
\hline 2003 & & $3(2)$ & $12(0)$ & $1(1)$ & $0(0)$ & & $3(4.50)$ \\
\hline 2004 & & $0(1)$ & $10(2)$ & $2(0)$ & $0(0)$ & & $3(1.33)$ \\
\hline 2005 & & $1(0)$ & $13(1)$ & $1(1)$ & $0(0)$ & & $2(0.58)$ \\
\hline 2006 & & $1(0)$ & $16(3)$ & $2(1)$ & $0(1)$ & & $5(2.69)$ \\
\hline 2007 & & $1(0)$ & $10(3)$ & $3(2)$ & $0(1)$ & & $6(5.69)$ \\
\hline 2008 & & $0(1)$ & $11(2)$ & $1(0)$ & $0(1)$ & & $4(2.31)$ \\
\hline 2009 & & $0(1)$ & $14(1)$ & $6(3)$ & $0(0)$ & & $5(3.08)$ \\
\hline 2010 & & $1(0)$ & $6(6)$ & $0(2)$ & $0(0)$ & & $8(5.00)$ \\
\hline
\end{tabular}

Table 19. The annual hindcasts for tropical cyclone frequencies based on the work of LJ00 (for the 2000-2005 seasons), and forecasts (for 2006 - 2010) based on the results shown here. A simple point scoring system (I predicted - observed I) is used here. The table displays the observed value ( I difference from observed $I$ ). The value in parenthesis beside the total score is a $\chi^{2}$ score for that season (a lower score is a better forecast, or is a better "fit").

\subsection{Forecasting the $2006-2010$ seasons}

For the 2006 through 2010 seasons, a true forecast was made in the January and February time frame based on forecasts made for the upcoming ENSO phase. For example in 2010, the forecast was for the weak EN to die out and the onset of a LN-type season based on the SSTs (see Lupo et al. 2007, their table 1 and Fig. 19 here). A weak EN SST pattern set in during the late summer-to-early autumn during the 2009 hurricane season. In the Atlantic, the 2006 through 2009 forecasts were fairly good compared to the previous years, and this is likely due to the fact that during PDO2 years, the distribution of tropical cyclones was fairly similar across each phase of ENSO. Thus, an incorrect ENSO phase would not be as potentially damaging to the forecast as during PDO1 years where there were distinct differences across each ENSO phase. In 2010, the season was particularly active as a strong $\mathrm{LN}$ set in during the fall. The hurricane season peaked strongly in September, which is typical of a LN year, but the overall forecast was not as good due to the active East Atlantic. 
In the East Pacific, the 2006 and 2008 forecasts were relatively strong compared to the previous hindcasts, but 2007 and 2009 were weaker. The 2007 forecast was not very good even though the overall number of storms was close to what would be expected. There were more (fewer) TCs in the southwest (southeast) part of the East Pacific basin than expected. The 2006 (seven TS, five weak, three strong) and 2008 (nine TS, five weak, and two strong) TC intensity forecasts for this region was somewhat good, except that there were more strong storms observed in 2006 (eight TS, five weak, six strong) than expected. In 2008, there was one more tropical storm than expected. In 2007 and 2009, the intensity forecasts were more reliable; even if the overall numbers were lower (2007: 10 TS, three weak, one strong, and 2009: 12 TS, three weak, and five strong). In the East Pacific, the forecast in 2010 was a little worse as well. This was due to the fact that the southeast region and the East Pacific Basin as a whole were less active this year than at any other time since 1970.

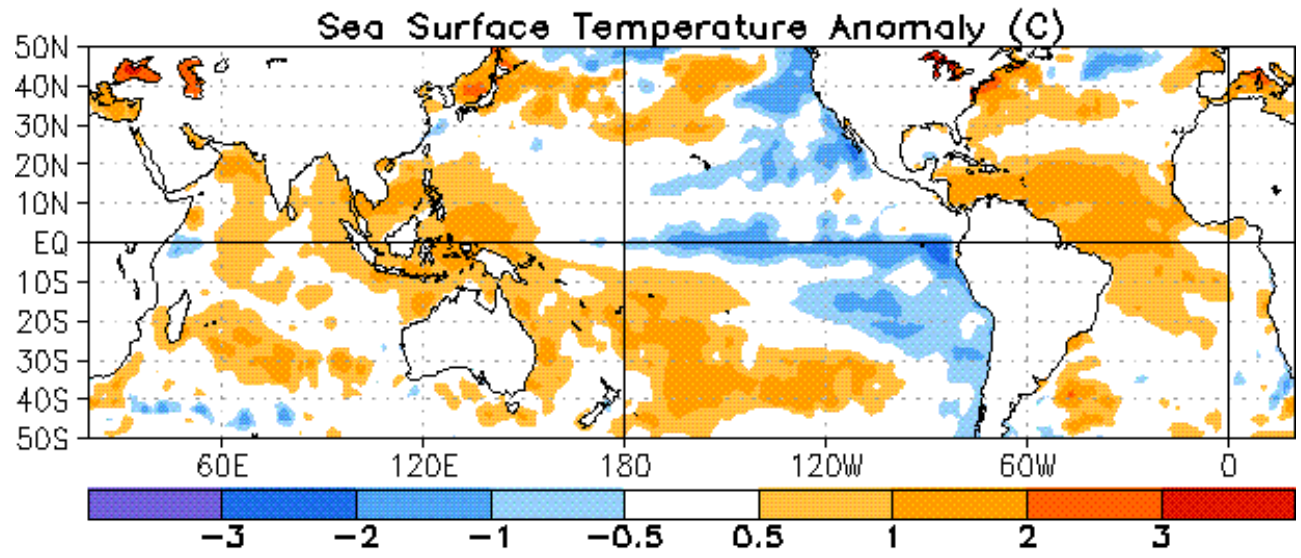

Fig. 19. A sample sea surface temperature anomaly $\left({ }^{\circ} \mathrm{C}\right)$ map from the month of July 2010 (source: Climate Prediction Center: Climate Diagnostics Bulletin). The anomalies are relative to the $1971-2000$ base period.

Similar TC forecasts for the upcoming seasons for the other basins based on this work could be formulated and would look like the following; West Pacific (northeast four, southeast five, southwest 13, northwest four, or ten TS, and eight each for the weak and intense hurricanes), North Indian (two west, three east, or three TS, and one each for the weak and intense hurricanes), and Southern Hemisphere (west Indian seven, east Indian ten, southwest Pacific seven, southeast Pacific five, and South Atlantic none, or 13 TS and eight each for the weak and intense hurricanes).

\section{Discussion, summary and conclusions}

The climatological behavior of TC activity for the entire globe was examined using the methodologies of LJO0 and Lupo et al. 2008. In the Atlantic and East Pacific, only an update to include the 2008 and 2009 seasons, as well as any re-categorization of hurricanes (e.g., Andrew - 1992) or ENSO years (e.g., 1974 becomes a LN year) was needed. In the West Pacific, a thorough breakdown of the hurricane and tropical storm activity from 1945 - 2009 was examined, as well as the activity in the North Indian Ocean (1977 - 2009), and the 
Southern Hemisphere $(1980$ - 2010). We also briefly examined the activity in the South Atlantic (1960 - 2010).

The major finding from this work that was common across the entire globe was that it is not enough to look at the interannual variations of TC occurrence and intensity, especially if one is to forecast the occurrence of TCs in a given region. In each of the ocean basins, there was some ENSO related variability in the number and or intensity of TCs found. In many cases, this variability did not rise to the level of statistical significance until the data were stratified by phases of the PDO. In general, the ENSO related variability was smaller during the cool phase of the PDO. This type of behavior was noted in studies of other phenomena as well (e.g., Berger et al. 2003; Lupo et al. 2005). In contrast, during PDO1 years, ENSO variability was enhanced. For, example, in the Atlantic and Indian Ocean basins, there were more TC, and more intense TC during LN years than during EN years, and these results were statistically significant. In the East Pacific and West Pacific, EN years produced more TCs, and this was especially notew orthy in PDO1 years. In the East Pacific, there were more TCs in EN years among the weaker hurricanes and TS, while in the West Pacific, more of the TC were intense hurricanes. In the $\mathrm{SH}$, the interdecadal variability was more subtle and there was more TC during PDO1 years. Additionally, there was an increase in the proportion of intense ENSO year TCs during the latest two decades.

Also, it was found that there were no statistically significant trends in global TC activity, neither in any of the basins nor over the globe as a whole. Several studies (e.g. Zuki and Lupo, 2008, and Chan, 2009) demonstrate that TC formation and maintenance are not solely a function of favorable oceanic or atmospheric conditions only. Thus, it is not clear how climate changes may influence TC numbers. In most basins, interannual variability resulted in a shift in the primary TC genesis regions rather than large changes overall. In the Atlantic, the increased LN TC activity was the result of more active sub-regions such as the Gulf of Mexico, the Caribbean, and the East Atlantic. In the combined Pacific regions, LN (EN) years tended to have more TC activity along the continental coastal margins than the Central Pacific (across the entire tropical Pacific). In the North and South Indian Ocean regions, as well as the Southeast Pacific, there were more TCs in LN years, while there was little TC variability in the East Indian Ocean or the southwest Pacific.

An examination of the length of TC seasons and when the peak would occur reveal interannual differences. In the Atlantic Ocean basin, the TC season extends from June to October (July to November) in EN (LN) years, with the weaker (stronger) peak in September. In the East Pacific basin, the EN TC season is longer than LN TC season by roughly one month as both begin in June and EN TC seasons extend into November. In this basin, the peak is stronger during EN years and was clearly in August, while the LN peak was in July and August. In the West Pacific, the seasonality was similar to the East Pacific. The EN (LN) TC year was two months longer (shorter) and peaked in August (July and August). While this ocean basin is considered to be active all year, there was clearly a minimum in TC activity during February and March, and in LN PDO1 years, the season was considerably shorter than any other period in the West Pacific (June - December, with a peak in September).

The Indian Ocean Basin was different from all other global basins in that there were two periods of strong TC activity in May and June, and again in October to December. In LN (EN) years, the maximum activity periods were stronger and longer (weaker and shorter), and encompassed May/ June (May) and October/ November (November). Finally, in the SH, 
the seasonal activity was two months longer (shorter) for EN (LN) years, extending from October to May (November to April). However, the LN year had a much stronger and longer period of peak activity.

Finally, it is shown that this work may have some forecasting utility by using the same forecasting / hindcasting methods of LJ00 and Lupo et al. (2008), except here we assigned each season from 2000 - 2005 a forecast score based on a statistical distribution calculation. This approach included assuming that the ENSO forecast was correct. While the TC hindcasts for most of these years were reasonable, more seasons will be needed in order to evaluate what would constitute a good score in each basin. TC forecasts have been made since the 2006 season; and in the Atlantic, the forecasts were relatively good. In the Pacific, the TC season forecasts were relatively poor for the 2007 and 2009 seasons, while the forecasts for 2006 and 2008 have been relatively good. The poor forecasts may have been due to a poor ENSO forecasts. Additionally, the year 2010 forecasts were made and will be evaluated later. This work, however, is preliminary and data from additional seasons will be used to verify our approach.

\section{Acknowledgements}

The authors would like to thank the reviewers for their helpful comments in making this work stronger. We would like to also thank Dr. Nathan Mantua at the Joint Institute for the study of Atmosphere and Ocean (JISAO - http:/ / jisao.washington.edu) for providing us with Figure 2.

\section{References}

Berger, C.L., Lupo, A.R., Browning, P., Bodner, M., Rayburn, C.C., Chambers, M.D. (2003). A climatology of Northwest Missouri snowfall events: Long term trends and interannual variability. Phys. Geog., Vol. 14, 427 - 448.

Birk, K., Lupo, A.R., Guinan, P.E., and Barbieri, C.E. (2010). The interannual variability of Midwestern temperatures and precipitation as related to the ENSO and PDO. Atmofera, Vol. 23, 95 - 128

Chan, J. C. L. (1985). Tropical cyclone activity in the northwest Pacific in relation to the El Niño/ Southern Oscillation phenomenon, Mon. Wea. Rev., Vol. 113, 599-606.

Chan, J.C.L. (1995). Tropical cyclone activity in the western north Pacific in relation to the stratospheric Quasi- Biennial Oscillation, Mon. Wea. Rev., Vol. 123, 2567-2571.

Chan, J.C.L. (2007). Interannual variations of intense typhoon acitivity. Tellus, Vol. 59A, 455460.

Chan, J.C.L. (2009). Thermodynamic control on the climate of intense tropical cyclones. Proc. R. Soc., A, Vol. 495, 3011- 3021.

Chan, J.C.L. and Liu, K.S. (2004). Global warming and western North Pacific typhoon activity from an observational perspective. cl Climate, Vol. 17, 4590-4602.

Collins, J.M. (2007). The relationship of ENSO and relative humidity to interannual variations of hurricane frequency in the North-East Pacific Ocean. Papers of the Appl. Geog. Conf., Vol. 30, 324-333.

Collins, J.M. (2010). Contrast High North-East Pacific Tropical Cyclone Activity with Low North Atlantic Activity. Southeastern Geog., Vol. 50, No. 1, 83-98. 
Davis, M.A.S., Brown, G.M., and Leftwich, P. (1984). A tropical cyclone data tape for the Eastern and Central North Pacific Basins, 1949-1983: Contents, Limitations, and Uses. NOAA Technical Memorandum NWS NHC 25, Coral Gables, Florida, 20 pp.

Deser, C., and Phillips, A.S. (2006). Simulation of the 1976/ 1977 climate transition over the North Pacific: Sensitivity to Tropical Forcing. el Clim, Vol. 19, 6170-6180.

Deser, C., Capotondi, A., Saravanan, A.R., and Phillips, A.S. (2006). Tropical Pacific and Atlantic climate variability in CCSM3. el Clim, Vol. 19, 2451 - 2481.

Deser, C., Phillips, A.S., and Hurrell, J.W. (2004). Pacific interdecadal climate variability: Linkages between the tropics and North Pacific during the boreal winter since 1900. I Clim, Vol. 17, 3109 - 3124.

Elsner, J.B., Kara, A.B., and Owens, M.A. (1999). Fluctuations in North Atlantic hurricane frequency. I Clim, Vol. 12, $427-437$.

Emanuel, K. (2005). Increasing destructiveness of tropical cyclones over the past 30 years. Nature, Vol. 436, 686.

Enfield D. B. and Mestas-Nuñez, A.M. (1999). Multiscale variabilities in global sea surface temperatures and their relationships with tropospheric climate patterns. CI Clim. Vol. 12, 2719-2733.

Gershanov, A., and Barnett, T.P. (1998). Inderdecadal modulation of ENSO teleconnections. Bull. Amer. Meteor. Soc., Vol. 79, 2715 - 2725.

Goldenberg, S.B., and Shapiro, L.J. (1996). Physical mechanisms for the association of El Niño and West African rainfall with Atlantic major hurricane activity. I Climate, Vol. 9, 1169 - 1187.

Gray, W. M. (1968). Global view of the origin of tropical disturbances and storms. Mon. Wea. Rev., Vol. 96, 669-700

Gray, W.M. (1984a). Atlantic season hurricane frequency. Part 1: El Niño and $30 \mathrm{mb}$ Quasi Biennial Oscillation influences. Mon. Wea. Rev., Vol. 112, 1649 - 1668.

Gray, W.M. (1984b). Atlantic season hurricane frequency. Part 2: Forecasting its variability. Mon. Wea. Rev., Vol. 112, 1669 - 1683.

Gray, W.M. (1979). Hurricanes: Their formation, structure, and likely role in the tropical circulation. Meteorology over the Tropical Oceans, pp. 155 - 218, D.B. Shaw, ED., Royal Meteorologocal Society.

Gray, W.M., Sheaffer, J.D. and Landsea, C.W. (1997) Climate trends associated with multidecadal variability of Atlantic hurricane activity. Hurricanes, Climate, and Socioeconomic Impacts, 15 - 53. Springer, Berlin, H.F. Diaz and R.S. Pulwarty, Eds.

Henderson-Sellers, A., Zhang, H., Berz, G., Emanuel, K., Gray, W.M., Landsea, C.W., Holland, G., Lighthill, J., Shieh, S.L., Webster, P., and McGuffie, K. (1998) Tropical cyclones and global climate change: A post - IPCC assessment. Bull. Amer. Meteor. Soc., Vol. 79, 19 - 38.

Hurrell J. W., van Loon, H., and Shea, D.J. (1995). The mean state of the troposphere. NCAR Tech Memo \# NCAR/ CAS/ 95-08, D. Karoly and D. Vincent eds., 83 pp.

Jarvinen, B.R., Neumann, C.J., and Davis, M.A.S. (1984). A tropical cyclone data tape for the North Atlantic Basin, 1886 - 1983: Contents, limitations, and uses. NOAA Tech. Memo. NWS NHC 22, Coral Gables, Florida, 21 pp.

Kossin, J.P., and Vimont, D.J. (2007). A more general framework for understanding Atlantic hurricane variability and trends. Bull. Amer. Meteor. Soc., Vol. 88, 1767-1781. 
Lander, M. A. (1994). An exploratory analysis of the relationship between tropical storm formation in the western North Pacific and ENSO, Mon. Wea. Rev., Vol. 122, 636651.

Lander, M. A., and C. P. Guard (1998). A look at global tropical cyclone activity during 1995: Contrasting high Atlantic activity with low activity in other basins. Mon. Weather Rev., Vol. 126, 1163- 1173.

Landsea, C.W. (1993). A climatology of intense (or Major) Atlantic hurricanes. Mon. Wea. Rev., Vol. 121, 1703 - 1713.

Landsea, C.W., Pielke Jr., R.A., Mestas-Nuñez, A.M., and Knaff, J. (1999) Atlantic Basin hurricanes: Indicies of climate changes. Climatic Change, Vol 42, 89 - 129.

Lupo, A.R., Oglesby, R.J., and Mokhov, I.I. (1997) Climatological features of blocking anticyclones: A study of Northern Hemisphere CCM1 model blocking events in present-day and double $\mathrm{CO}_{2}$ atmospheres. Clim. Dyn., Vol. 13, 181-195.

Lupo, A.R., and Johnston, G.J. (2000). The variability in Atlantic Ocean Basin hurricane occurrence and intensity as related to ENSO and the North Pacific Oscillation. Nat. Wea. Dig., Vol. 24, No. 1,2, 3-13.

Lupo, A.R., Albert, D., Hearst, R., Market, P.S., Akyuz, F.A., and Allmeyer, C.L. (2005). Interannual variability of snowfall events and snowfall-to-liquid water equivalents in Southwest Missouri. Nat. Wea. Dig., Vol. 29, 13-24.

Lupo, A.R., Kelsey, E.P., Weitlich, D.K., Mokhov, I.I., Akyuz, F.A., Guinan, P.E., Woolard, J.E. (2007). Interannual and interdecadal variability in the predominant Pacific Region SST anomaly patterns and their impact on a local climate. Atmosfera, Vol. 20, 171- 196.

Lupo, A.R., Latham, T.K., Magill, T., Clark, J.V., Melick, C.J., and Market, P.S. (2008). The interannual variability of hurricane activity in the Atlantic and East Pacific Regions. Nat. Wea. Dig., Vol. 32, No. 2, 119-135.

Mantua, N.J., Hare, S.R., Zhang, Y., Wallace, J.M., and Francis, R.C. (1997). A Pacific Interdecadal Climate Oscillation with Impacts on Salmon Production. Bull. Amer. Meteor. Soc., Vol. 78, 1069-1079.

McAdie, C.J. and Rappaport, E.N. (1991). Diagnostic Report of the NHC, Vol. 4, No. 1, NOAA, NHC, Coral Gables, FL, 45 pp

McTaggart-Cowan, R., Bosart, L. F., Davis, C. A., Atallah, E. H., Gyakum, J. R., and Emanuel, K. A. (2006). Analysis of Hurricane Catarina (2004). Mon. Wea. Rev., Vol. 134, 3029-3053.

Mestas-Nuñez, A. M., and Enfield, D.B. (1999). Rotated global modes of non-ENSO sea surface temperature variability. el Clim. Vol. 12, 2734-2746.

Minobe, S. (1997). A 50 - 70 year climatic oscillation over the North Pacific and North America. Geophys. Res. Lett., Vol. 24, 683 - 686.

Minobe S. (2000). Spatio-temporal structure of pentadecadal variability over the North Pacific. Prog. Oceanogr. Vol. 47, 381-408.

Neter, J., Wasserman, W., and Whitmore, G.A. (1988). Applied Statistics, 3rd edition. Boston: Allyn and Bacon, 1006 pp.

Ng, K.W.E., and Chan, J.C.L. (2010). Interannual variations of tropical cyclone activity over the Northern Indian Ocean. Int. el Clim., under review.

Pielke, R.A., and Landsea, C.W. (1999). La Niña, El Niño, and Atlantic hurricane damages in the United States. Bull. Amer. Meteor. Soc., Vol. 80, 2027 - 2033. 
Pielke, R. A., Jr., Landsea, C.W., Mayfield, M., Laver, J., and Pasch, R. (2005). Hurricanes and global warming. Bull. Amer. Meteor. Soc., Vol. 86, 1571- 1575.

Ramage, C. S., and Hori, A.M. (1981). Meteorological aspects of El Niño. Mon. Wea. Rev., Vol. 109, 1827-1835.

Reagan, M.R., Franklin, A.D., Market, P.S., and Lupo, A.R. (2005). The South Atlantic hurricane ("Catarina") of March 2004. The 30th Annual Meeting of the National Weather Association, 15 - 20 October, 2005, St. Louis, MO.

Schultz, L.W. (2007). Some climatological aspects of tropical cyclones in the eastern north Pacific. Nat. Wea. Dig., Vol. 32, No. 1, 45-54.

Simpson, R.H. (1974). The hurricane disaster potential scale. Weatherwise, Vol. 27, 169 and 186.

Vimont, D.J., and Kossin, J.P. (2007). The Atlantic meridional mode and hurricane activity. Geophys. Res. Lett., Vol. 34, L07709, doi:10.1029 2007GL029683.

Vincent, D.G. (1994). The South Pacific Convergence Zone (SPCZ): A Review. Mon. Wea. Rev., Vol. 122, 1949-1970

Wang, B., and Chan, J.C.L. (2002). How strong ENSO events affect tropical storm activity over the western north Pacific. I Clim., Vol. 15, 1643- 1658.

Webster, P.J., Holland, G.J., Curry, J.A., and Chang, H.R. (2005). Changes in tropical cyclone number, duration, and intensity in a warming environment. Science, Vol. 309, 1844 1846.

Wilks D. S. (2006). Statistical Methods in the Atmospheric Sciences, 2nd ed. Int. Geophys Series, Vol. 91, Academic Press, 627 pp.

Wu, G., and Lau, N.C. (1992). A GCM simulation of the relationship between tropical storm formation and ENSO, Mon. Wea. Rev., Vol. 120, 958-977.

Zuki, Md. Z., and Lupo, A.R. (2008). The interannual variability of tropical cyclone activity in the southern South China Sea. I Geophys. Res., Vol. 113, D06106, doi:10.1029/ 2007.D009218 - 14 . 


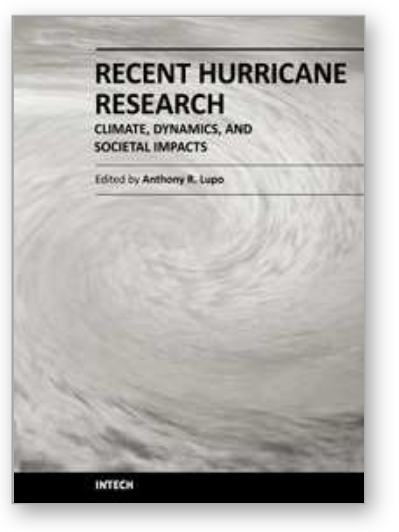

\author{
Recent Hurricane Research - Climate, Dynamics, and Societal \\ Impacts \\ Edited by Prof. Anthony Lupo
}

ISBN 978-953-307-238-8

Hard cover, 616 pages

Publisher InTech

Published online 19, April, 2011

Published in print edition April, 2011

This book represents recent research on tropical cyclones and their impact, and a wide range of topics are covered. An updated global climatology is presented, including the global occurrence of tropical cyclones and the terrestrial factors that may contribute to the variability and long-term trends in their occurrence. Research also examines long term trends in tropical cyclone occurrences and intensity as related to solar activity, while other research discusses the impact climate change may have on these storms. The dynamics and structure of tropical cyclones are studied, with traditional diagnostics employed to examine these as well as more modern approaches in examining their thermodynamics. The book aptly demonstrates how new research into short-range forecasting of tropical cyclone tracks and intensities using satellite information has led to significant improvements. In looking at societal and ecological risks, and damage assessment, authors investigate the use of technology for anticipating, and later evaluating, the amount of damage that is done to human society, watersheds, and forests by land-falling storms. The economic and ecological vulnerability of coastal regions are also studied and are supported by case studies which examine the potential hazards related to the evacuation of populated areas, including medical facilities. These studies provide decision makers with a potential basis for developing improved evacuation techniques.

\title{
How to reference
}

In order to correctly reference this scholarly work, feel free to copy and paste the following:

Anthony R. Lupo (2011). The Interannual and Interdecadal Variability in Hurricane Activity, Recent Hurricane Research - Climate, Dynamics, and Societal Impacts, Prof. Anthony Lupo (Ed.), ISBN: 978-953-307-238-8, InTech, Available from: http://www.intechopen.com/books/recent-hurricane-research-climate-dynamics-andsocietal-impacts/the-interannual-and-interdecadal-variability-in-hurricane-activity

\section{INTECH}

open science | open minds

\author{
InTech Europe \\ University Campus STeP Ri \\ Slavka Krautzeka 83/A \\ 51000 Rijeka, Croatia \\ Phone: +385 (51) 770447 \\ Fax: +385 (51) 686166 \\ www.intechopen.com
}

\author{
InTech China \\ Unit 405, Office Block, Hotel Equatorial Shanghai \\ No.65, Yan An Road (West), Shanghai, 200040, China \\ 中国上海市延安西路65号上海国际贵都大饭店办公楼 405 单元 \\ Phone: +86-21-62489820 \\ Fax: +86-21-62489821
}


(C) 2011 The Author(s). Licensee IntechOpen. This chapter is distributed under the terms of the Creative Commons Attribution-NonCommercialShareAlike-3.0 License, which permits use, distribution and reproduction for non-commercial purposes, provided the original is properly cited and derivative works building on this content are distributed under the same license. 